\title{
When Ribonucleases Come into Play in Pathogens: A Survey of Gram-Positive Bacteria
}

\author{
Brian C. Jester, Pascale Romby, and Efthimia Lioliou \\ Architecture et réactivité de l'ARN, UPR 9002 CNRS, IBMC, Université de Strasbourg, 15 rue René Descartes, \\ 67084 Strasbourg, France
}

Correspondence should be addressed to Efthimia Lioliou, e.lioliou@ibmc-cnrs.unistra.fr

Received 17 October 2011; Accepted 27 November 2011

Academic Editor: John Tagg

Copyright ( $\odot 2012$ Brian C. Jester et al. This is an open access article distributed under the Creative Commons Attribution License, which permits unrestricted use, distribution, and reproduction in any medium, provided the original work is properly cited.

It is widely acknowledged that RNA stability plays critical roles in bacterial adaptation and survival in different environments like those encountered when bacteria infect a host. Bacterial ribonucleases acting alone or in concert with regulatory RNAs or RNA binding proteins are the mediators of the regulatory outcome on RNA stability. We will give a current update of what is known about ribonucleases in the model Gram-positive organism Bacillus subtilis and will describe their established roles in virulence in several Gram-positive pathogenic bacteria that are imposing major health concerns worldwide. Implications on bacterial evolution through stabilization/transfer of genetic material (phage or plasmid DNA) as a result of ribonucleases' functions will be covered. The role of ribonucleases in emergence of antibiotic resistance and new concepts in drug design will additionally be discussed.

\section{Introduction}

Bacterial pathogens predominantly respond to environmental changes, such as entry into a host, by adapting their physiology through altered gene expression. The gene products that give a pathogen an enhanced chance of survival within the host are termed virulence factors. Pathogens use a variety of different mechanisms to regulate virulence gene expression. Besides transcriptional control, several posttranscriptional mechanisms have been well documented in the literature $[1,2]$. In the recent years, messenger RNA (mRNA) stability emerges as a major player controlling the expression levels of proteins that allow pathogenic bacteria to thrive within the host. The stability of mRNA is dictated by the activity of ribonucleases (RNases) that act either alone or in the presence of small regulatory RNAs (sRNAs) and/or with ancillary proteins. The stability of mRNA also depends on growth stage, environmental cues, or stresses (such as the presence of nutrients, metabolites) as well as cell-density, a phenomenon known as quorum sensing $[3,4]$.

A variety of posttranscriptional regulatory strategies involve RNases. The cell can directly control global RNA decay by adjusting the levels of RNases $[4,5]$. Studies using
Escherichia coli and Bacillus subtilis have given a detailed knowledge about the mechanisms of RNA decay and maturation for Gram-negative and Gram-positive bacteria [6, 7]. For instance, posttranscriptional control mediated by sRNAs and RNases is particularly important as it provides the cell with a means to adapt rapidly to sudden environmental changes and stresses. Moreover, it is energetically less costly as it bypasses the need for new protein synthesis. Additionally, fast removal of the sRNA regulator when the stress is over allows the cell to recover and return to its previous genetic program [1]. The advent of new technologies such as deep-sequencing and tiling arrays revealed a plethora of sRNAs and antisense RNAs (asRNAs) encoded in the bacterial genomes [8-11]. Although their functions and the conditions under which they are expressed are only now starting to be understood, we expect a lot of exciting discoveries in the field of RNA regulation.

In this paper, we will primarily focus on RNase-mediated regulation of virulence gene expression in medically relevant Gram-positive bacteria. Different mechanisms will be presented showing that RNases can either activate or repress gene expression. The involvement of RNases in bacterial antiviral defense, transfer of mobile genetic elements and 
persistence will be presented. We discuss the genomic context within which RNases are embedded and how the conservation of patterns amongst several genomes can give us insight into their expression. Perspectives on the design of new generation antibiotics targeting several components of the RNA degrading machinery will be underscored.

\section{The RNA Decay Machinery}

Decades of research have resulted in the identification/ characterization of several RNases within B. subtilis. An exhaustive overview of these is beyond the scope of this paper and we refer readers to some high-quality review articles that cover this topic $[5,7]$. Instead, with an emphasis on the most recent discoveries, we will present the works done in B. subtilis for specific RNases where homologues in pathogens have been associated with virulence. RNases are broadly divided into two groups: (1) exoribonucleases, which degrade RNA substrates from either the $5^{\prime}$ or $3^{\prime}$ end and (2) endoribonucleases that cleave internally within an RNA molecule. The orchestration of mRNA decay in Grampositive bacteria by the concerted action of several RNases is illustrated schematically in Figure 1.

2.1. RNase $Y$. Recently, an essential gene within B. subtilis ( $y m d A$ ) was determined to be involved with RNA processing and was renamed RNase $Y[12,13]$. RNase $Y$ cleaves unpaired regions of RNA and subsequent work demonstrated that RNase $\mathrm{Y}$ is the functional equivalent to RNase $\mathrm{E}$ in E. coli, the major single-strand specific endoribonuclease which initiates RNA processing and degradation [14]. Interestingly, changes in expression levels of RNase $\mathrm{Y}$ within B. subtilis resulted in altered stability of polycistronic mRNAs required for biofilm formation [15], but this phenotype may be attributed to a polar effect on expression of the downstream gene, $y m d B$, which has been shown to be required for biofilm formation [16]. RNase Y was reported to be involved in riboswitch turnover, as well as to affect global mRNA decay $[12,15]$. Recent data from distant bacteria show that RNases such as E. coli RNase E and B. subtilis RNase $\mathrm{Y}$ are not evenly distributed in the cytoplasm but that a fraction is localized at the membrane $[17,18]$. Although it is not known whether the localization is a regulated process, the transmembrane domain of RNase $\mathrm{Y}$ is essential for the activity of the enzyme in vivo [14]. Therefore, these data suggest that RNA turnover is somehow compartmentalized in the cell and that the spatial organization of RNases in bacteria is an additional layer of regulation.

2.2. RNases $\mathrm{J} 1$ and J2. B. subtilis RNase $\mathrm{J} 1 / \mathrm{J} 2$ have been the subject of intensive research recently. RNases J1 and J2 were first identified and characterized in B. subtilis as the component that endonucleolytically cleaved the thrS leader mRNA [19]. Earlier work in B. subtilis demonstrated that only RNase J1 is essential for growth [20]. Size exclusion chromatography reveals that recombinant RNase J1 from B. subtilis elutes as both a homodimer and a tetramer [21]. RNases J1/J2 are bifunctional and possess both endoribonuclease and $5^{\prime}-3^{\prime}$ exoribonuclease activities [19,22]. Additionally, these two proteins can form a heterodimeric complex that has unique cleavage site specificities and efficiency [23].

The exoribonuclease activity of RNase J2 has been shown to be significantly less efficient compared to RNase J1 [23]. The $5^{\prime}-3^{\prime}$ exonuclease activity, previously not identified in bacteria, appears to be the major function in vivo [23]. It has been demonstrated that RNase J1 is involved with global RNA turnover and with processing of $16 \mathrm{~S}$ and $23 \mathrm{~S}$ rRNAs $[24,25]$. The $5^{\prime}$ triphosphate of primary transcripts and/or the presence of a hairpin structure at the $5^{\prime}$ end protect RNA from degradation by the exoribonuclease activity of RNase $\mathrm{J} 1[22,26]$. RNases J1/J2 have been found associated with the Gram-positive degradosome complex [13,27] (discussed below).

The first structure solved for RNase J1 was from Thermus thermophilus [26]. The protein consists of three domains, a core $\beta$-lactamase domain, a $\beta$-CASP domain, that is specific to members of the $\beta$-lactamase superfamily of enzymes acting on nucleic acids, and a unique $\mathrm{C}$-terminal domain, that is joined by a flexible linker to the $\beta$-lactamase domain. Two catalytic zinc $(\mathrm{Zn})$ ions were found in a cleft between the $\beta$-lactamase and $\beta$-CASP domains. However, this structure, bound to a UMP substrate, appeared to be in a closed conformation that could not explain the $5^{\prime}$ monophosphate substrate preference nor did it reveal the mechanism for the dual-enzyme activities [26]. The structure of a catalytically inactive mutant form of RNase J1 associated with a 4 nt RNA sequence has recently provided new insights for the mechanisms of the dual enzymatic activities and RNA binding [28]. The binding of the RNA induces a change in the relative position of the three domains with respect to each other as well as specific alterations in conformation of the specific $\beta$ CASP and $\beta$-lactamase domains. These movements result in a widening of the narrow catalytic cleft between the domains creating a channel that is wide enough for a single-stranded RNA to enter. The cleaved nucleotide is discharged from the other side through a negatively charged exit tunnel [28]. The binding of RNA causes major rearrangements within the $\beta$ CASP domain where specific loop regions are displaced by up to $12 \AA$ to accommodate the substrate. The RNA binding pocket consists of positively charged residues that extend beyond the cleavage site, giving a rationale for the binding of longer RNA transcripts and the endoribonucleolytic activity. The recently solved structure and modeling of B. subtilis RNase J1 has revealed a similar pattern of conformational changes upon substrate binding [21].

2.3. PNPase. In B. subtilis, the nonessential multifunctional PNPase $(77 \mathrm{kDa})$ is the major exonucleolytic RNase, that forms a trimer to catalyze the $3^{\prime}$ to $5^{\prime}$ phosphorolytic degradation of RNA [29-31]. Additionally, under certain conditions, PNPase is able to add nucleotides to the $3^{\prime}$ end of RNA [32]. The 3' binding and processivity of PNPase appear to be blocked by strong hairpin secondary structures such as Rho-independent terminators, which are often found at the ends of $B$. subtilis transcripts and the processivity was inhibited by the Not I sequence (GCGGCCGC) [33]. Thus, 


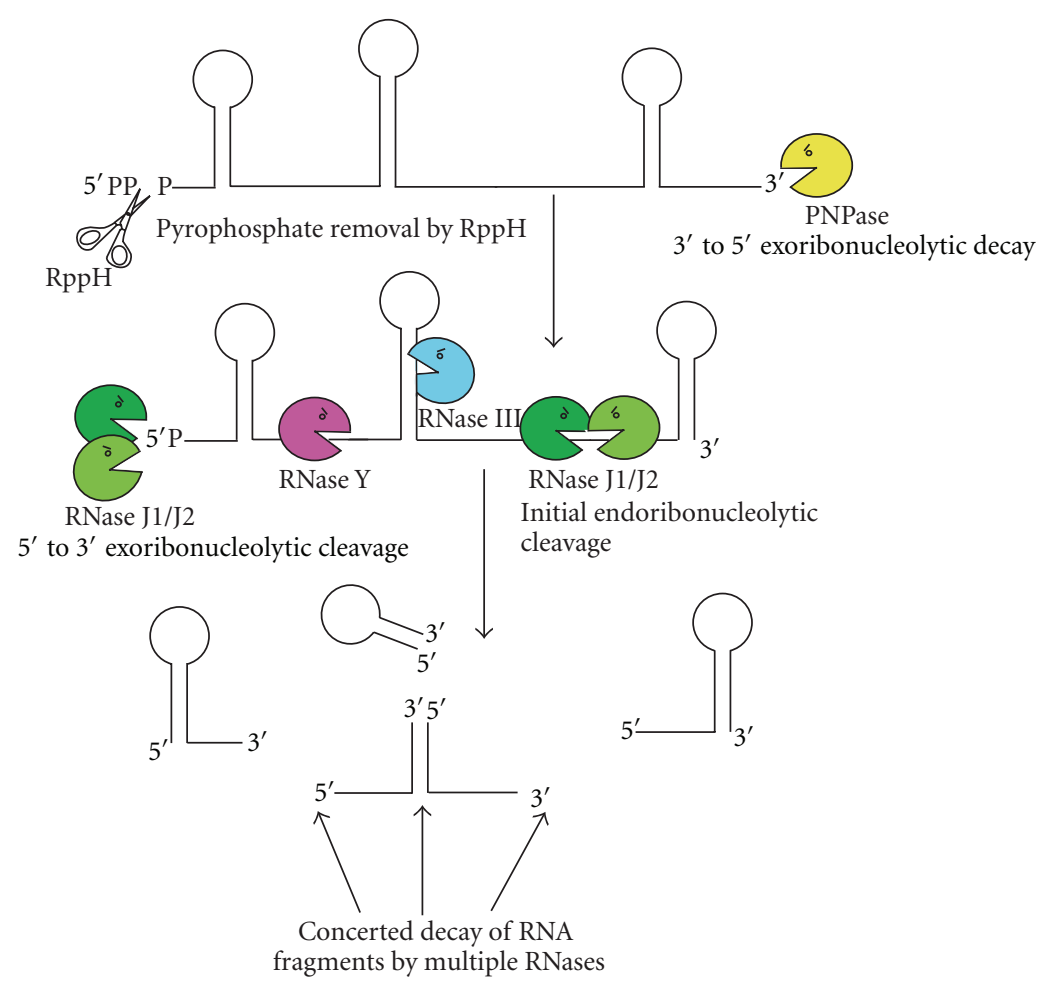

Figure 1: Diagram illustrating RNA decay by the RNases involved in virulence in Gram-positive bacteria. Removal of pyrophosphate from the $5^{\prime}$ end of mRNA by $\mathrm{RppH}$ is represented by the scissors. The degradation of RNA via the $3^{\prime}$ end is mediated by the $3^{\prime}$ to $5^{\prime}$ exoribonucleolytic activity of PNPase (in yellow). RNases J1 and J2 (in green) cleave RNA endoribonucleolytically and exoribonucleolytically in the 5' to 3' direction. RNase Y (in pink) and the dsRNA-specific RNase III (in blue) cleave RNA endoribonucleolytically.

it is believed that PNPase plays the secondary step in RNA decay and that the degradation of nucleotides only occurs after the $3^{\prime}$ end becomes exposed due to an endonucleolytic cleavage by another RNase (RNase III, RNase Y, or RNase $\mathrm{J} 1 / \mathrm{J} 2)[7]$.

It is interesting to mention some of the remarkable new functions discovered involving this versatile protein. Recently, PNPase was found to copurify with B. subtilis RecN and this complex was able to degrade single-stranded DNA (ssDNA) in vitro [34]. The exonucleolytic activity of PNPase on ssDNA was characterized and a functional role for PNPase in homologous DNA recombination in B. subtilis was identified [34]. Extending from this work the same group was able to show that $B$. subtilis PNPase catalyzes templateindependent polymerization of dNDPs onto $3^{\prime}$ ends of ssDNA [35]. This work has led to the establishment of a molecular model for the role of PNPase in DNA repair [35].

2.4. RNase III. Bacterial RNase III belongs to the Class I RNase III family of enzymes, while Classes II and III include the eukaryotic Drosha and Dicer, respectively, which are involved in biogenesis of siRNA/miRNA in higher organisms (reviewed in $[3,36,37]$ ). The bacterial RNase III is the smallest of RNase III family members consisting of a catalytic and a dsRNA binding domain [38]. It functions as a homodimer with dimerization occurring through the ribonuclease domains [39]. Recently, a fourth class of RNase III enzymes was found with the discovery of the endoribonuclease Mini
III, which is involved with the final steps of maturation of $23 \mathrm{~S}$ rRNA. This enzyme lacks three out of four dsRNA binding domains and consists of only the catalytic domain [40]. The structures of bacterial as well as eukaryotic RNase III enzymes have helped in understanding their functions (reviewed in [36]).

RNase III is a $\mathrm{Mg}^{2+}$-dependent double-strand-specific endoribonuclease capable of cleaving dsRNA. It recognizes a variety of structures such as imperfect duplexes, helices interrupted by bulged residues, kissing loops, and stacked helices [41-44]. Cleavage by RNase III produces the characteristic type of dsRNA with a $5^{\prime}$ phosphate and a $3^{\prime}$ hydroxyl group and a 2 nt $3^{\prime}$-overhang (reviewed in [5-7]). RNase III is involved in the maturation of large ribosomal RNAs in E. coli and B. subtilis [45] as well as in the regulation of single and polycistronic mRNAs [5-7, 46]. Moreover, it is involved in the maturation of other housekeeping RNAs such as the small cytoplasmic RNA (scRNA) precursor in B. subtilis [47-49]. No consensus sequence motif has been defined for this enzyme but "antideterminants" have been proposed to prevent the recognition of RNA molecules by $E$. coli RNase III [50].

2.5. RNase $P$. RNase $\mathrm{P}$ is a ribonucleoprotein particle that contains at least one protein subunit and a single-ribozyme subunit [51]. In B. subtilis, RNase P has been shown to cleave precursor tRNAs and tmRNA forming the mature $5^{\prime}$ end and to cleave the adenine riboswitch which stabilizes the 
downstream mRNA transcript $[52,53]$. The catalytic site is located in the RNA subunit [54]. Crystal structures of RNase $P$ either alone [55] or bound to tRNA [56] reveal that the RNA-RNA recognition occurs through shape complementarity and conserved intermolecular contacts. The active site structure and the conserved RNase P-tRNA contacts suggest a universal mechanism for catalysis. Since biochemical and structural mechanisms for recognition and cleavage of RNA substrates by RNase P have been characterized in-depth by several groups, we refer the readers to an excellent recent review for a comprehensive summary of this work [57].

2.6. $R p p H$. In E. coli, RNA pyrophosphohydrolase (RppH) removes a pyrophosphate from the $5^{\prime}$ end of RNA, converting the triphosphate into a monophosphate, a reaction that occurs before RNA degradation by RNase E [58]. The finding that a $5^{\prime}$ triphosphate on RNA is a poor substrate for RNase J1/2 in B. subtilis [19] inspired Richards et al. [59] to search for the functional RppH homologues in B. subtilis. Bioinformatic searches identified six putative homologues with canonical Nudix hydrolase motifs. To identify the functional $\mathrm{RppH}$, these proteins were expressed and assayed for the deprotection event in vitro. They identified an $\mathrm{RppH}-$ dependent $B$. subtilis transcript by constructing a $\triangle r r p H$ strain and screening for mRNAs with altered half-lives [59]. Detailed study of the processing of a polycistronic mRNA reveals that $\mathrm{RppH}$ converts the $5^{\prime}$ triphosphate to a monophosphate mRNA prior to degradation by RNase J1. Even though the RppH has not yet been implicated in virulence, this discovery reveals an additional stage in the elegant orchestration of RNA decay. This mechanism is reminiscent of the decapping step that triggers mRNA degradation in eukaryotes [60].

2.7. The Existence of a Degradosome in Gram-Positive Bacteria. The degradosome has been first discovered and characterized in E. coli [61-63]. A degradosome complex within Gram-positive bacteria has remained elusive until recently [13]. While screening for in vivo interaction partners of glycolytic enzymes within B. subtilis, several proteins known to be involved with RNA processing and degradation were identified [13]. The primary protein-protein interactions were further evaluated using the bacterial twohybrid approach. The Gram-positive degradosome consists of three RNases (RNase J1/J2, RNase Y), polynucleotide phosphorylase (PnpA) and two glycolytic enzymes (phosphofructokinase and enolase) [13]. Further characterization identified a DEAD box RNA helicase (CshA) that interacts with RNase Y and PnpA [27]. This helicase was predicted to be localized at the membrane since the protein carries a $\mathrm{N}$-terminal transmembrane domain similar to the sequence present on RNase Y [27]. Recently, the degradosome from $S$. aureus has been characterized and evaluated using the bacterial two-hybrid approach [64]. Although this work confirmed the conservation of the B. subtilis multienzymatic complex, different partner interactions were described and additionally, the association of the protein subunit of ribonuclease P (RnpA) with CshA was demonstrated [64].
2.8. Genomic Context of RNases. The importance of genomic organization and operon structure for gene expression has been well documented [65]. Often genes with similar function or associated to the same biosynthetic pathway tend to be found within the same operon or in close proximity on the chromosome. Combining genomic information from several public databases (NCBI, genolist, and Biocyc.org), we analyzed the conservation of genetic organization across four families of pathogenic Gram-positive bacteria additionally including B. subtilis. Using the multigenome alignment tool (http://www.biocyc.org/), the genomic context was aligned for several Gram-positive organisms (see Figures 1-8 in Supplementary material available online at doi: 10.1155/2012/ 592196). Some of the most noteworthy features are highlighted below.

Several of the genes ( $p n p A, r n j B, r n y)$ for the proteins involved in the degradosome are located in a relative close proximity to each other on the chromosome and genetic arrangements appear to have evolved in Gram-positive species (Figure 3). However, a loose conservation of $p n p A-$ $r n j B$-rny gene cluster is observed among the genomes. Interestingly, the presence of $r p s O$ upstream of $p n p A$ is found in all genomes and in E. coli as well, suggesting that $p n p A$ and $r p s O$ are ancient genes of a common origin. In $B$. subtilis, $p n p A$ is part of a polycistronic operon located $8 \mathrm{~kb}$ upstream of $r n j B$, and the $r n j B$ operon is sandwiched between two chromosomal regions that contain several sporulation genes. In $S$. aureus, $p n p A$ and $r n j B$ are located directly next to each other (Figure 3). In Clostridia species, no RNase J2 homologue was found, but a large genomic rearrangement has brought $p n p A$ relatively close to rny. In Listeria species, a very different genomic context is observed, where large genomic insertions separate the genes of this cluster. The proximity of $p n p A-r n j B-r n y$ locus within several Grampositive organisms may have functional consequences. For instance, located within the same locus are certain genes that have been identified to cross-regulate expression and activity. The enzymatic activity of PNPase on single-stranded DNA is in part modulated by RecA, a gene located upstream of $r n y$ [35]. Decay of the highly conserved $r p s O$ mRNA is initiated by RNase Y followed by PNPase [66]. Recently, in Streptomyces coelicolor, it has been shown that transcripts originating at the $r p s O$ promoter read-through into $p n p A$ and become processed by RNase III [67].

The clustering of RNase genes, along with several genes for sporulation, cell wall peptidoglycan biosynthesis, motility, and cell division are also noteworthy. In E. faecalis, cotranscribed with $r n j B$ are two genes involved with cell wall biosynthesis and $r n j B$ has been shown to regulate pili formation at the posttranscriptional level [68]. In $B$. subtilis, RNase Y ( $r n y / y m d A)$ is the first gene of a bicistronic operon including $y m d B$ which was recently shown to play a critical role in the bistable expression of genes involved in flagella and biofilm formation [16]. Moreover, the genes located upstream of $r n y, p g s A$ (cell wall biosynthesis), $\operatorname{cin} A$ (competence-damage inducible regulator), and $\operatorname{rec} A$ (member of SOS regulon) are relatively conserved among Gram-positive bacteria. The gene encoding CshA, the RNA helicase of the degradosome in B. subtilis [27], is also part of 
an operon including two genes encoding proteins involved in peptidoglycan biosynthesis. The genomic context of this operon is conserved in other species (see Supplementary Figure 8). RNase III ( $r n c)$ is transcribed as the first of a threegene operon in B. subtilis, also encoding the essential smc (chromosome condensation and segregation ATPase) and fts $Y$ (signal recognition particle) [69]. This organization is also highly conserved in all Gram-positive species (see Supplementary Figure 2).

Transcriptomic array data for S. aureus $[74,75]$ reveal that all RNases are expressed in vegetative growth. At the transition to stationary phase, the levels either (i) drop dramatically and remain low thereafter for RNase J2, RNase $\mathrm{Y}$, and RNase P or (ii) reduce slightly only to catch back later into stationary phase for RNase J1, PNPase, and RNase III. The reduced transcript levels of several $S$. aureus RNases in stationary phase $[74,75]$ appear to correlate with the demand for peptidoglycan/ribosome biosynthesis.

\section{Ribonucleases Acting in Virulence}

3.1. Global Roles of RNases in Virulence. The role of several RNases in virulence has been recently studied in two major pathogenic bacteria, Streptococcus pyogenes and Staphylococcus aureus. S. pyogenes (group A Streptococci, GAS) and S. aureus cause mild to systemic and life threatening diseases. The emergence of methicillin resistant $S$. aureus strains acquired both in hospitals and, in the community, has resulted in more deaths annually than HIV in the United States in recent years $[76,77]$.

GAS transcripts have been recently classified into two Classes, I and II, depending on their stability during stationary phase of growth [78]. Class I transcripts appear very labile during stationary phase, while Class II transcripts encoding several virulence factors such as sagA (streptolysin S), sda (DNase), and arc (arginine deiminase) have prolonged half-lives. It has been shown that the $3^{\prime}-5^{\prime}$ exonucleolytic activity of PNPase is responsible for degrading substrates of class II after an elongated lag phase where mRNAs are stable [79]. The initial endoribonucleolytic cleavage of Classes I and II transcripts is mediated by RNases $\mathrm{J} 1$ and $\mathrm{J} 2$, which are essential in GAS $[78,80]$. It was proposed that Class I transcripts are better substrates for RNases J1 and $\mathrm{J} 2$ and only after their depletion, degradation of Class II transcripts is initiated. The amounts of RNases J1, J2, and PNPase as well as putative signals they respond to, might be critical for such growth phase-dependent regulation.

The roles of ribonucleases in virulence gene expression are summarized in Table 1. RNase Y, encoded by cvfA in Streptococcus and Staphylococcus, has been shown to affect virulence in both pathogenic bacteria in silkworm and murine models [81-83]. In $S$. pyogenes, a cvfA deletion affected expression of several virulence factors [82]. Moreover, microarray analysis revealed differential expression of $29 \%$ of genes indicative of the importance of RNase $\mathrm{Y}$ in the initiation of mRNA decay [82]. These data suggested that RNase $Y$ mediated downregulation of metabolism and upregulation of certain virulence factors facilitates the acquisition of cellular components from the host. The effect of RNase Y on virulence gene expression occurred mainly in stationary phase [82] in agreement with data showing that virulence factor expression in $S$. pyogenes is strictly dependent on growth phase [84]. RNase Y-mediated regulation was shown to be dependent on the nutritional status of the cells implying that the enzyme is involved is sensing the nutrient availability (directly or indirectly) [82]. However, its deletion did not affect the ppGpp levels, therefore the observed effects were not linked to stringent response [82]. S. pyogenes RNase $\mathrm{Y}$ interacts with the glycolytic enzyme enolase [82] which might provide a link between nutritional status and RNase Y-mediated gene expression. RNase Y has been reported to affect production of virulence factors in $S$. aureus either through expression of the accessory gene regulatory locus, agr or independently [83]. Biochemical analyses revealed that the predicted phosphohydrolase domain (HD domain) of RNase $\mathrm{Y}$ possesses a phosphodiesterase activity against $2^{\prime}, 3^{\prime}$ cyclic nucleotide and this activity is required for virulence [83]. RNase $\mathrm{Y}$ was predicted to contain a transmembrane domain in S. pyogenes and S. aureus $[82,83]$, similar to the B. subtilis enzyme [17].

Studies have indicated that the capacity of $S$. aureus to differentially express subsets of virulence factors according to stress and growth phase is largely attributed to mRNA stability [4]. In particular, it was shown that mRNA stabilization occurs in stationary phase as well as under cold-, heat-, acid-, and alkaline-shock and the stringent response $[85,86]$. The authors showed that PNPase affected bulk mRNA decay and was shown to be essential for cold-growth [4] as is the case for E. coli, Salmonella enteric, and several Yersinia species (reviewed in [87]). In addition, RNase $\mathrm{P}$ was also described as a major RNase involved in bulk mRNA degradation that has direct consequences on the expression of virulence factors at the stationary phase of growth [75]. Interestingly, rnpAdepleted cells exhibited attenuated virulence in a mouse infection model [75].

\subsection{RNases and Mechanisms of Regulation of Specific Genes in Pathogenic Bacteria}

3.2.1. sRNA and RNases Activating Gene Expression. The activation of an $\mathrm{S}$. pyogenes mRNA encoding a virulence factor (ska, streptokinase) depends on the presence of a sRNA, FasX [70]. FasX binds to ska mRNA 30 nts upstream of the AUG and forms a 7 nts-long helix. This double-stranded structure leads to an increased stability of the mRNA (Figure 2(a)). Notably, a C-rich sequence motif present on FasX is employed for the interaction, similarly to what has been described for S. aureus RNAIII and other sRNAs [71, 88]. Deletion of either RNase Y or PNPase did not result in stabilization of ska mRNA indicating that FasX-dependent stabilization is due to a limited access of RNases at the $5^{\prime}$ end [70]. Whether the $5^{\prime}-3^{\prime}$ exoribonucleolytic property of RNases J1 and J2 is responsible for ska mRNA degradation, remains to be tested.

Within Clostridium perfringens, the VirR/VirS two-component system regulates several virulence genes including transcription of the 386 nts sRNA, VR-RNA [89]. Recent 


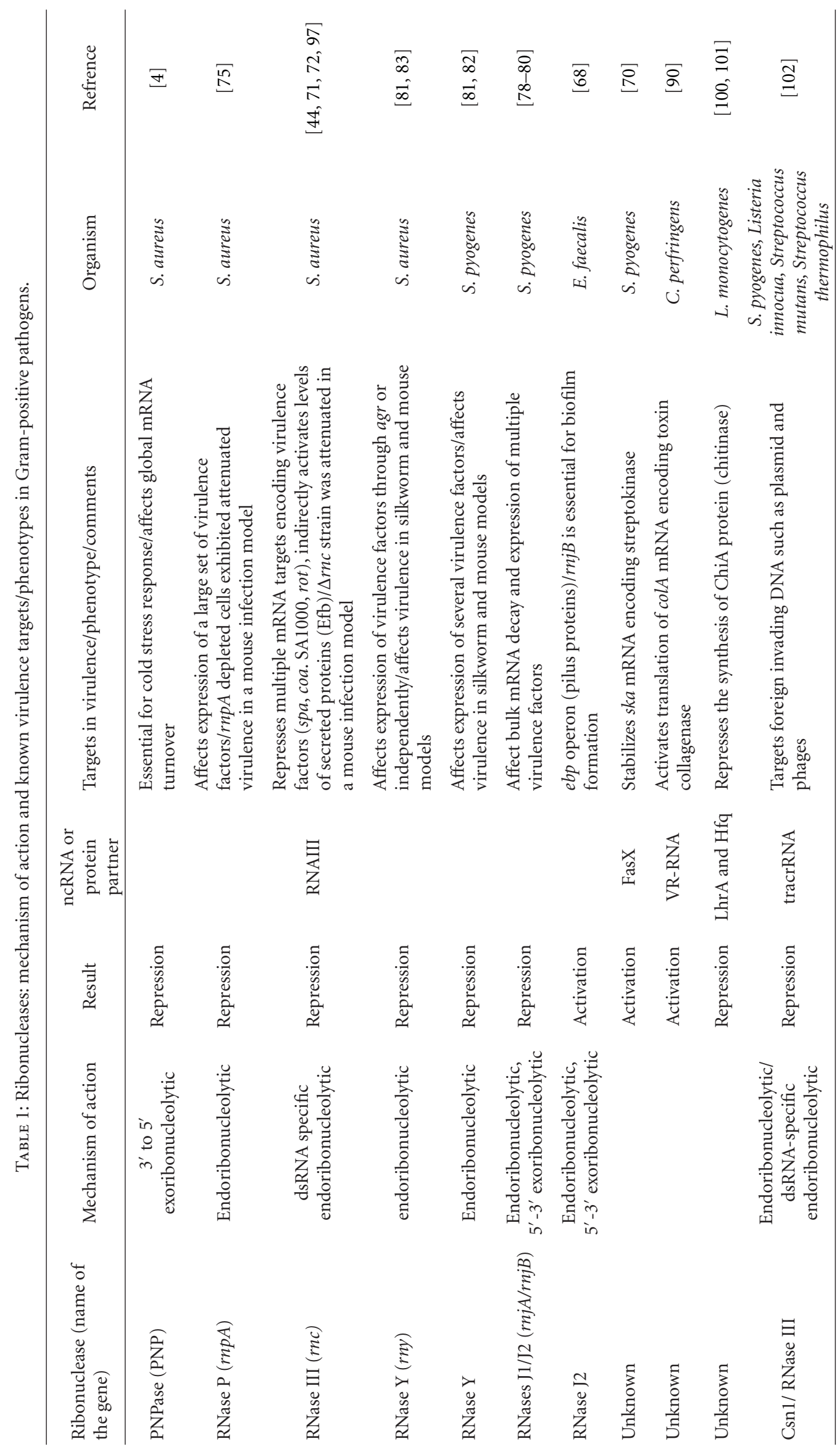




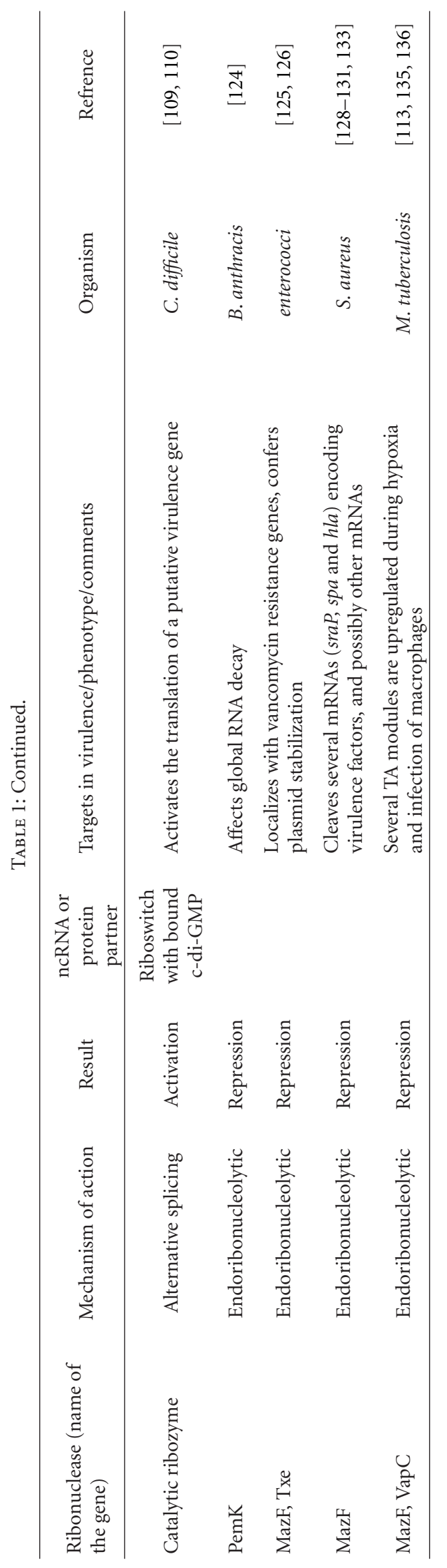




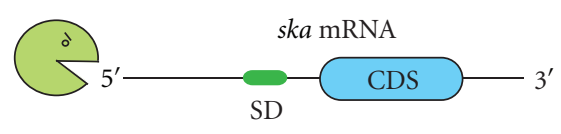

mRNA degradation

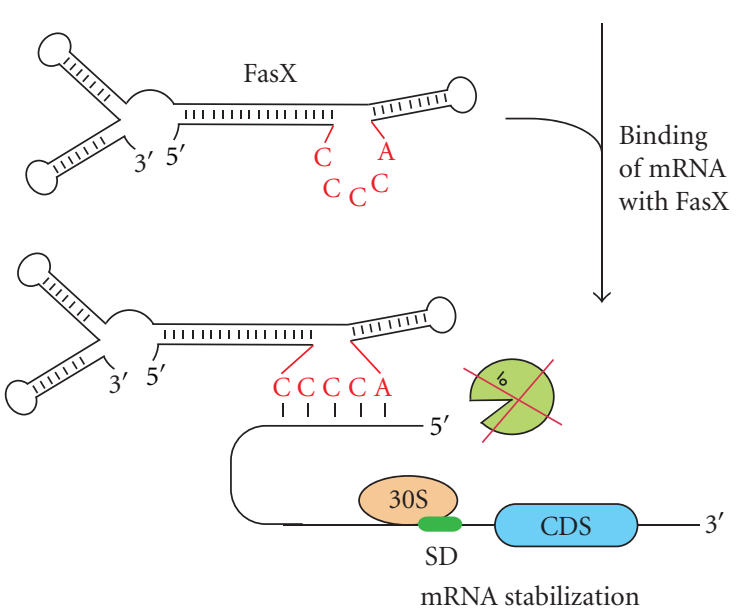

(a)

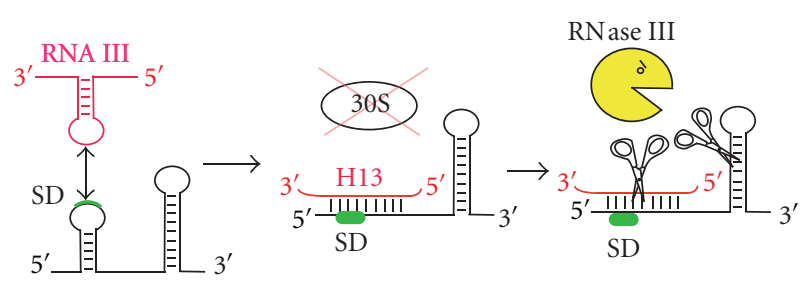

Repression of translation of SA1000/spa mRNAs

(b)

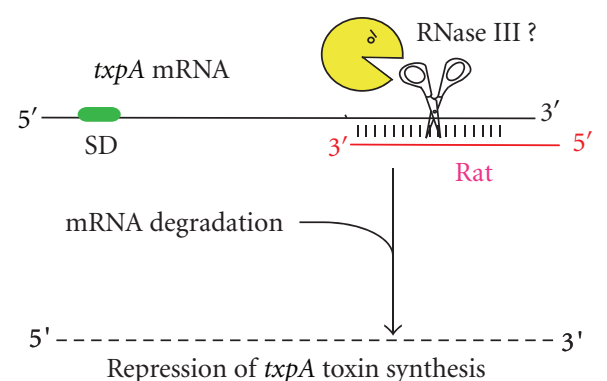

(c)

FIgURE 2: Diagram illustrating different mechanisms of posttranscriptional regulation. (a) Stabilization of $S$. pyogenes ska mRNA. Transcript levels of ska are regulated by RNase-mediated decay. Under stress conditions, the FasX sRNA is expressed and binds to the $5^{\prime}$ leader region of ska mRNA inhibiting RNase degradation [70]. (b) S. aureus RNAIII/RNase III repression of translation. The quorum-sensing regulatory RNAIII uses a regulatory hairpin to bind to spa mRNA (or SA1000) target sequence. The initial loop-loop interaction is converted to a duplex sequestering the Shine-Dalgarno sequence (SD). Access of the ribosome is blocked and translation is repressed. RNase III is recruited to the hybrid region and to an additional hairpin present in spa and cleaves the transcript making the regulatory event irreversible [71, 72]. (c) Repression of B. subtilis TxpA toxin synthesis. The asRNA Rat is transcribed convergently and is fully complementary to the txpA mRNA. Binding of Rat asRNA to txpA transcript induces rapid degradation of the mRNA [73]. The RNase performing the initial cleavage might be RNase III although the nature of the enzyme and the structure of the hybrid are not yet determined.

work by Obana et al. [90] has shed light onto the VR-RNAdependent regulation of the toxin collagenase ( colA). Base pairing of VR-RNA with the 5'UTR of colA mRNA induces cleavage by an unknown RNase immediately downstream of the colA-VR-RNA duplex. This processing in turn leads to the formation of a shorter hairpin and increased mRNA stability in vivo. Mutational analysis of the RBS indicates that ribosome binding to the processed mRNA additionally stabilizes the colA mRNA [90].

Hence, the secondary structure of mRNA has an important role in controlling transcript stability as highlighted by the two examples for ska and colA mRNAs [70, 90]. Interestingly we have shown that in S. aureus, RNase III mediates transcript stabilization of $\operatorname{csp} A$ mRNA, encoding a coldshock protein, through processing of a long hairpin structure in the $5^{\prime}$ UTR. This processing leads to the formation of a short but stable hairpin that enhances the stability of the mRNA and its translation (Lioliou et al., submitted).

Enterococcus faecalis is an opportunistic Gram-positive responsible for many nosocomial infections [91]. Recently, Gao et al. [68] showed that the E. faecalis $r n j B$, encoding RNase J2, is involved in the regulation of pilus gene expression and biofilm formation. Pili expression is important for pathogenicity of many Gram-positive organisms [92]. Inactivation of $r n j B$ results in destabilization of $e b p$ operon transcript encoding the pilus proteins [68]. The mechanism of action by which RNase J2 stabilizes the mRNA and whether this regulation takes place in other Gram-positive bacteria producing pili remains to be shown.

3.2.2. sRNA and RNases Repressing Gene Expression. The effect of RNase III in virulence in $S$. aureus has been well documented. Specifically, in stationary phase, RNase III acts together with the agr encoded regulatory RNAIII [93] to repress the expression of several adhesin factors and the repressor of toxins, $\operatorname{Rot}[44,71,72]$. RNAIII is a multifunctional RNA that encodes a virulence factor, hemolysin delta. Through its $3^{\prime}$ UTR, RNAIII interacts with mRNAs either by forming imperfect duplexes or by promoting the formation of loop-loop interactions. In cases where translational repression occurs, the Shine-Dalgarno is sequestered and ribosome binding is prevented. RNAIIImRNA complexes in turn constitute targets for RNase III cleavage to render regulation irreversible (Figure 2(b)). Translational repression of Rot indirectly results in the activation of toxins and in the repression of adherence factors. As more functions of regulatory RNAs are unveiled $[8,88,94-96]$, it is predicted that other sRNAs, such as the group I toxin-antitoxin systems, might act coordinately with RNase III to regulate gene expression. In a recent report, it was shown that a $\Delta r n c$ strain was attenuated in a murine infection model, and that RNase III is involved in the regulation of extracellular protein secretion, such as the extracellular fibrinogen binding protein Efb in S. aureus [97]. 


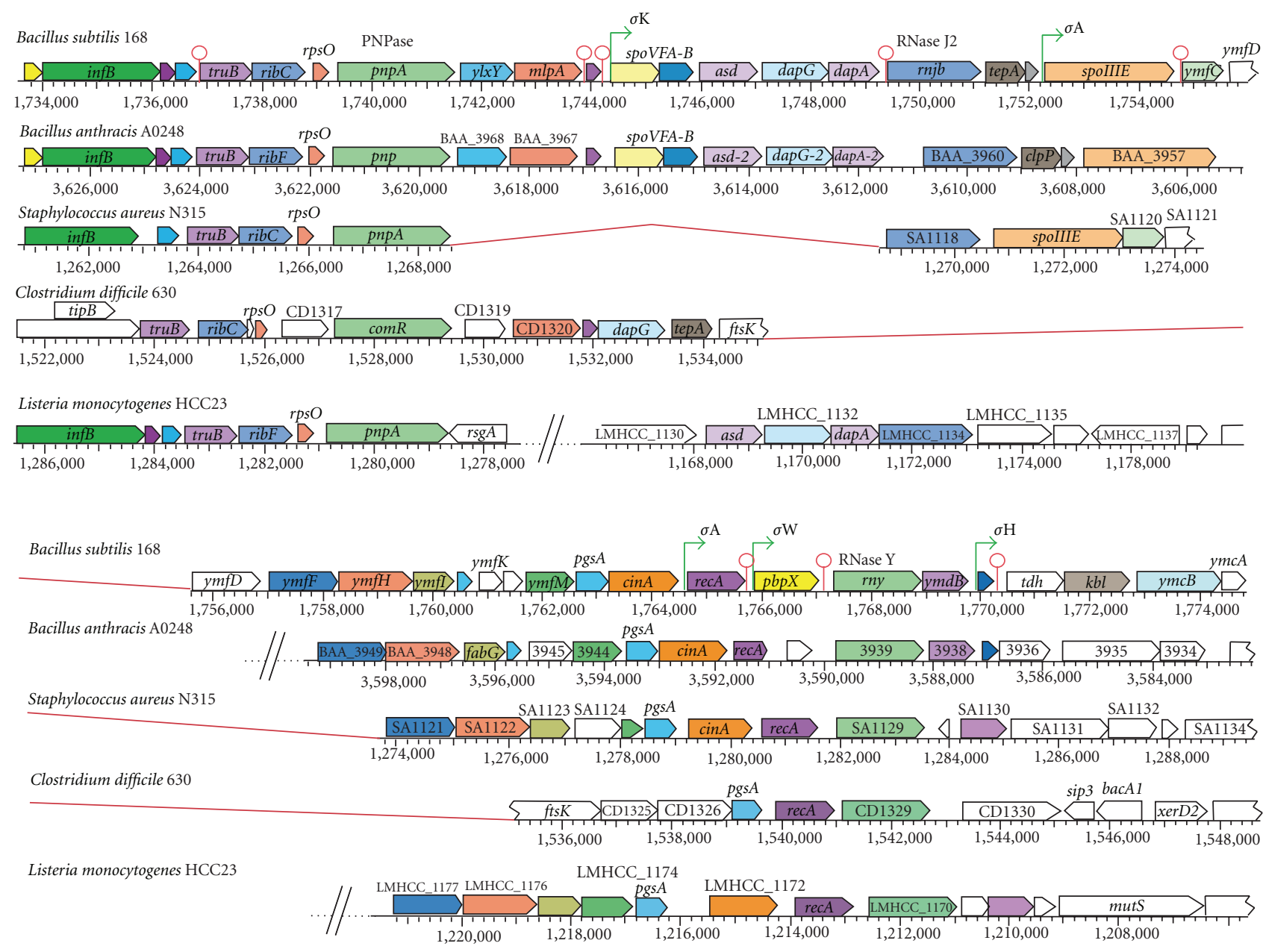

Figure 3: Alignment of the genomic context for three components of the RNA degradosome. Homologues of PNPase, RNase J2, and RNase Y were aligned from the different Gram-positive organisms, Bacillus subtilis 168, Bacillus anthracis A0248, Staphylococcus aureus N315, Clostridium difficile 630, and Listeria monocytogenes HCC23. Alignments were made using the multigenome alignment tool on http://www.biocyc.org/. Red lines indicate directly adjacent regions of the chromosome and the diagonal lines indicate a chromosomal gap. Genes that are conserved in bacteria are shown with the same color.

This was achieved through regulation of the levels of $\sec Y 2$ mRNA encoding a protein of the accessory secretory system.

In Gram-negative bacteria, Hfq has been shown to be a critical component of sRNA-mediated regulation [98]. Evidence of a similar role for $\mathrm{Hfq}$ in Gram-positive bacteria has remained elusive until recently [99]. Work by Nielsen et al. [100] showed that within Listeria monocytogenes, translational regulation of lmo0850 mRNA mediated by the binding of LhrA sRNA is dependent on Hfq. The specific RNases involved in the degradation of the lmo0850 transcript still remain to be determined. Additionally, a lhrA deletion within L. monocytogenes altered the expression levels of approximately 300 genes, including chiA, a known virulence factor that encodes a chitinase [101].

3.2.3. RNase and Defense Mechanism: CRISPR. Recently, the role of RNase III in bacterial immunity against phages and plasmids has been demonstrated [102]. CRISPR/Cas (clustered, regularly interspaced short palindromic repeats/ CRISP-associated proteins) systems mediate bacterial immunity against foreign invading DNA, such as plasmid and phages. The CRISPR genetic loci encode for spacer-repeat sequences as well as their associated Cas endoribonucleases. The repeat sequence is usually identical and can be found between 2-249 times within a locus. The spacer sequences are unique and originate from phage or plasmid sequences that have been integrated in the genome and which subsequently confer immunity against the specific phage or against plasmid conjugation [103-107]. The CRISPR loci are transcribed as a long pre-crRNA, which is then matured into small RNAs (crRNA) consisting of a single spacer-repeat unit, which effectively attacks foreign DNA. Processing of pre-crRNA into crRNAs is usually performed by the Cas endoribonucleases. However, some Cas homologues are absent from certain subtypes of CRISPR systems as in S. pyogenes, which lacks three Cas proteins, Cse3 (CasE), 
Cas6, and Csy4. In these cases, the host-encoded RNase III mediates maturation of the pre-crRNA acting in concert with a trans-encoded RNA (trans-activating CRISPR RNA, tracrRNA) and the endoribonuclease Csn1 [102]. Particularly, it has been reported that tracrRNA interacts with almost perfect complementarity with the repeat units in the precrRNA. In a first processing event, RNase III cleaves specifically the duplexes and subsequently, a second cleavage occurs in the spacer sequence. The exact mechanism underlying the second processing event and whether it is carried out by Csn1 remains to be elucidated. Csn1 also aids the interaction of the two RNAs and possibly stabilizes the tracrRNA. This type of regulation was found conserved in other bacteria such as Listeria innocua, Neisseria meningitides, Streptococcus mutans, and Streptococcus thermophilus. Based on examination of several bacterial genomes, it was suggested that tracrRNA possibly co-evolved with the repeat sequences of crRNA [102].

\subsubsection{Unusual RNases: Riboswitches with Catalytic Activities.} Riboswitches are cis-acting regulatory RNA sequences that control expression of downstream genes by binding metabolites that induce structural changes to the transcript [108]. An interesting study recently highlighted the regulatory importance of cyclic-di-GMP [109]. In this study, a new class of c-di-GMP riboswitch was identified that is linked in tandem to an allosteric self-splicing ribozyme upstream of a putative virulence gene within the genome of Clostridium difficile. Binding of c-di-GMP to this RNA structural motif induces folding changes at the splice site causing a different splicing pattern. The binding of c-di-GMP results in the inclusion of a perfect RBS directly upstream of a nonconventional UUG translational start codon. Without the second messenger signal, c-di-GMP, the final spliced mRNA lacks the RBS and is not translated [110]. This work illustrates a new level of posttranscriptional complexity within bacteria.

The discovery of the mechanism for transcript destabilization induced by the $g \operatorname{lm} S$ ribozyme has demonstrated how the cell can sense nutritional status and modulate gene expression accordingly using catalytic RNA cleavage followed by RNase-mediated decay [111]. In B. subtilis, glucosamine6-phosphate binds to the $g l m S$ ribozyme stimulating sitespecific RNA self-cleavage in vivo. This cleavage results in transcripts that contain a $2^{\prime}-3^{\prime}$ cyclic phosphate at the $3^{\prime}$ end and a hydroxyl group at the $5^{\prime}$ end. After cleavage, the downstream transcript is rapidly degraded. It was shown that targeting of $g \operatorname{lm} S$ RNA for degradation was due to the $5^{\prime}$ hydroxyl end which was a substrate for the $5^{\prime}-$ $3^{\prime}$ exoribonuclease activity of RNase J1 [111]. This work demonstrates that metabolite-sensing ribozymes enable the cell an efficient means to respond to their environment.

3.2.5. Toxin-Antitoxin Systems and Stress Response. Toxinantitoxin (TA) systems are continuously being discovered across bacterial species. Their involvement in phage resistance, plasmid maintenance, stress responses, and bacterial persistence is well documented (for reviews, see [112-118]). These systems are classified into three main types. In the first one, the antitoxin is a noncoding RNA (ncRNA), which is antisense to the mRNA encoding the toxin. For type II, both toxin and antitoxin are proteins. Type III (ToxIN) was recently discovered and employs an antitoxic sRNA, which binds and inhibits a protein toxin. For type II and III systems, the toxin and the antitoxin are cotranscribed as part of an operon, whereas for type I systems the two genes are encoded on the opposite strands overlapping in their $5^{\prime}$ - or $3^{\prime}$-ends. In all cases the antitoxin, RNA or protein, is labile and subject to degradation, while the toxin is stable. Upon conditions that favor elimination of the antitoxin, the TA complex is disrupted, and the toxin is released (or translated) to exert its toxic effect. Type I toxins usually consist of small hydrophobic peptides, the translation of which is turned off by antisense RNAs (asRNAs) [116]. In the case of E. coli hok/Sok and tis $A B /$ IstR systems, RNase III is the key enzyme which degrades the mRNA-asRNA complex [118]. Toxins of type II act usually as endoribonucleases (MazF and RelE) or inhibit DNA gyrase (CcdB) [112-114]. The E. coli MazF is an endoribonuclease cleaving mRNAs at a defined ACA consensus sequence independently of the ribosome, while RelE is a ribosome-dependent endoribonuclease that cleaves mRNAs positioned at the ribosomal A-site (reviewed in [112, 114]). The unique type III toxin, ToxN, was demonstrated to have endoribonuclease activity in vitro and was capable of cleaving its inhibitory antitoxic sRNA $[119,120]$. These data suggest that ToxN possibly acts as an RNase to inhibit translation and slow down bacterial growth. The mRNA targets of ToxN remain to be discovered.

The only type II TA system identified in B. subtilis so far is $n d o A I / n d o A$ where $n d o A$ encodes the toxin (EndoA, MazF homologue), which cleaves at unpaired UACAU sequences, and $n d o A I$ encodes the antitoxin $[121,122]$. Depending of the nature of the stress, the TA module in B. subtilis can be protective or lethal [123]. The authors hypothesized that this behavior would allow the cell a way to determine if the stress was mild enough to be repaired or so severe as to activate the cell death pathway [123]. Interestingly, a type I TA system encoded in the chromosome of $B$. subtilis was identified [73]. It consists of the TxpA toxin and its asRNA, RatA. The two RNAs are transcribed convergently overlapping at their $3^{\prime}$ ends. Pairing between $\operatorname{txp} A$-RatA leads to degradation of the mRNA by an unknown RNase (Figure 2(c)). Given its specificity for dsRNA, RNase III could be a good candidate to mediate the degradation. As the number of asRNAs found in bacterial genomes constantly increases [8-11], RNase III might prove to be an important player in this type of regulation.

The PemIK TA module from $B$. anthracis has recently been characterized [124]. The PemK was shown to be an endoribonuclease toxin that shares $96 \%$ similarity to the EndoA (MazF homologue) toxin from B. subtilis. Biochemical characterization of the TA module confirmed that PemI inhibits PemK-mediated endoribonuclease activity. The catalytic residues in PemK were defined in vitro, and surprisingly, the catalytic mutants retained the capacity to bind PemI efficiently [124]. The PemIK interaction was characterized in vitro giving clues to the conformational changes that take place following complex formation. 
Synthetic peptides were designed to disrupt the PemI-PemK interaction and to inhibit the endoribonuclease activity of PemK, demonstrating that TA modules can be potential antimicrobial targets [124].

The identification of MazEF and to a smaller extent axetxe, relBE, and $\varepsilon-\zeta$ homologues in plasmids of vancomycin resistance enterococci (VRE) isolated from patients [125] demonstrates their clinical importance. The authors showed that the MazEF system was transcribed and endowed enterococci with plasmid stability. Moreover, the mazEF genes were located on the same plasmid with the vancomycin resistance gene cluster, vanA. Recently, the axe-txe system was identified in a plasmid from Enterococcus faecium, which also encoded multiple drug resistances. The system was expressed in clinical isolates and Txe was shown to have endoribonucleolytic activity in vivo [126]. The presence of these systems in enterococcal plasmids might imply a role in the transfer of antibiotic resistance genes to other species such as MRSA [127] linking TA systems to development of virulence.

MazEF was also identified in S. aureus and the unpaired UACAU recognition sequence for endoribonucleolytic cleavage was established $[128,129]$. Induction of MazEF leads to destabilization of $\mathrm{sraP}$ mRNA which contains the consensus cleavage motif. The occurrence of the consensus sequence within coding sequences of other virulence factors was also demonstrated [129]. The induction of the MazEF had an effect on the expression of spa and hla mRNAs [130]. As mazEF and sigB are transcriptionally linked, sigB expression is partially dependent on factors affecting transcription of mazEF such as heat-shock and antibiotic stresses [131]. $\mathrm{SigB}$ was also shown to downregulate expression of mazEF, therefore creating a feedback inhibitory loop that possibly affects its own expression [131]. These findings have significant implications in mediation of stress responses and virulence as SigB is a major regulator of these biological processes in S. aureus [132]. Recently, the expression of a chromosomally encoded MazEF system in clinical isolates of MRSA strains was reported [133]. Therefore, this TA module is an important player in regulation of pathogenicity and might constitute a novel target for antibiotics.

Interestingly, it was recently shown that E. coli MazF cleaves preferentially ACA sequences in mRNAs located close by to the AUG codon thus generating leaderless mRNAs [134]. In addition, the enzyme also cleaves $16 \mathrm{~S}$ rRNA within the $30 \mathrm{~S}$ subunit and removes its last 43 nucleotides including the anti-Shine and Dalgarno sequence. This in turn creates a subpopulation of ribosomes that are able to translate the leaderless mRNAs [134]. Whether the formation of such specialized ribosomes produced under stress conditions can be generalized to all bacteria remains to be addressed.

Mycobacterium tuberculosis is a major worldwide health problem and in 2009 approximately 1.7 million people were estimated to have died from tuberculosis (WHO, Global tuberculosis control report 2011, WHO/HTM/TB/2011.16). Bioinformatic analyses revealed that $M$. tuberculosis encodes 88 putative TA systems, 30 of which were shown to be functional [135]. Remarkably, most of the TA systems were conserved within the M. tuberculosis complex (MTBC) while they were absent from closely related species. This implies that they were acquired after the speciation event and that they probably play a significant role in pathogenicity. The VapBC is the most abundant TA module in M. tuberculosis represented by 47 members. Subsets of VapBC modules were shown to be toxic when expressed and conversely this toxicity was counteracted by coexpression of the cognate VapB antitoxin $[135,136]$. VapC functions as an RNase in vitro and this may account for the inhibition of translation observed in vivo which profoundly affects gene expression in response to different environments and stresses $[135,136]$. Certain sets of TA systems were found upregulated under hypoxia and during infection of macrophages [135]. Previously, it was shown that the recognition sequences of MazF-mtb were less frequently present in proteins associated with pathogenicity (reviewed in [113]). Hence, certain TA modules can direct degradation of specific mRNAs in response to stress rather than inhibit bulk translation.

Interestingly, Winther and Gerdes [137] have shown that enteric VapC encodes a tRNase that cleaves initiator tRNA ${ }^{\mathrm{fMet}}$ between the anticodon stem and loop. Cellular depletion of tRNA $^{\mathrm{fMet}}$ had a bacteriostatic effect on cultures and production of VapB allowed cells to resume growth. The depletion of tRNA ${ }^{\text {fMet }}$ by VapC not only inhibited cell growth but was additionally found to activate initiation of translation at correctly positioned elongator codons. The authors further speculated that this mechanism has the potential to translate reading frames that were normally silent. This work in enteric bacteria has significant implications for virulence in Gram-positive organisms, particularly M. tuberculosis where VapBC modules are highly represented $[135,136]$. The oxidative burst within macrophages generates superoxide anion $\left(\mathrm{O}_{2}{ }^{-}\right)$and singlet oxygen, which can be lethal to cells [138]. A mechanism to globally reduce translation, such as cleavage of tRNA ${ }^{\mathrm{fMet}}$, would reduce the occurrence of toxic events and enhance survivability of the organism.

Bacterial persistence is a phenotype where part of the cell population enters a dormant nongrowing state which in turn confers resistance to antibiotics and other stresses [139]. The involvement of TA systems in development of persistence in E. coli was recently reported [140]. The authors showed that overexpression of the toxin led to the persister phenotype and that successive deletion of all TA systems in E. coli resulted in a dramatic decrease in formation of persisters [140]. Consistent with involvement of TA systems in the persistence phenotype, the transcriptome of persister M. tuberculosis revealed overexpression of TA systems [141].

The importance of the CRISPR systems in antiphage resistance was discussed earlier. Abortive infection (Abi) is mediated by the type III ToxIN systems and constitutes another mechanism by which bacteria defend against phages [142]. During Abi, a phage-infected bacterium altruistically commits suicide to prevent the spread of phage within the population. ToxIN systems were identified in the Gramnegative phytopathogen Erwinia carotovora but homologues are found in the genomes of several Gram-positive and Gram-negative pathogenic bacteria [120]. The hok/Sok (type I), MazEF (type II) systems have also been shown to confer 
phage resistance to their hosts (reviewed in $[112,118]$ ). This type of antiviral immune system could be critical for limiting horizontal transfer of phage encoded virulence factors between pathogenic species.

\section{Regulation of RNase Activity and RNA Stability: Emerging Issues}

4.1. RNases and sRNA-Dependent Regulation. RNases often act in concert with sRNAs and/or RNA binding proteins. Interaction with a sRNA can lead to occlusion of the ribosome binding to repress translation. Often an RNase is recruited to the site of interaction to degrade the mRNA making the regulation irreversible. It has also been proposed that in the absence of ribosome binding, the mRNA becomes more exposed to the action of RNases so that repression of translation can lead to rapid degradation $[3,5]$. Therefore, sRNAs are key players in fine-tuning mRNA levels. Most of our knowledge on sRNA stability comes from Gram-negative bacteria. In those cases examined, RNase III, PNPase, and RNase $\mathrm{E}$ are involved in the degradation of the sRNA, which can be coupled or uncoupled to that of the mRNA target [143-146]. Hfq is also an important player which protects the sRNAs against degradation [98]. Unexpectedly, sRNAs were recently shown to be destabilized in E. coli pnpA mutant cells in exponential phase of growth. It was proposed that PNPase protects sRNAs from degradation mediated by RNase E [144]. While S. aureus RNase III has been shown to initiate the decay of mRNAs repressed by the quorum sensing dependent RNAIII [87], little is known on the roles of RNases associated with the sRNA-dependent regulation in Gram-positive bacteria.

In the cases described so far where regulation of mRNA stability occurs through the combined action of a sRNA and a ribonuclease, the initial cleavage site is located within the mRNA-sRNA duplex as it is the case for RNase III [99] or proximal to the base-pairing region as exemplified for RNase E [1, 6]. A novel mode of action for E. coli RNase E was recently reported where the enzyme acts at a distance cleaving further into the coding sequence [147]. RNase E was found tethered to the RBS of $\operatorname{sodB}$ mRNA through association with Hfq and the sRNA RyhB which in turn occluded ribosome loading onto the RBS. When the mRNA was stripped of translating ribosomes, RNase E cleavage sites present within the coding sequence were exposed to the endonucleolytic activity of RNase E. Whether a similar mechanism exists in Gram-positive bacteria, remains to be elucidated.

Hfq, although a major player in sRNA-mediated degradation in Gram-negative bacteria [98], does not seem to have such an important role in RNA decay in Grampositive bacteria with one exception reported so far (see earlier). Other RNA binding proteins may carry out the role of Hfq. Interestingly, a conserved protein was found in Sinorhizobium meliloti, SMc01113/YbeY, which shares structural similarities with the MID domain of the Argonaute (AGO) proteins. Deletion of this protein induces pleiotropic effects as found for Hfq. Moreover, the protein regulates the accumulation of sRNAs and mRNAs similarly to Hfq [148]. This protein is conserved in Gram-positive bacteria although its function has not yet been studied in these organisms. In B. subtilis, three small basic proteins were proposed to act as RNA chaperones acting in concert with the sRNA FsrA, to promote degradation of transcripts encoding iron-using proteins under conditions of iron deprivation [149].

Hence, these examples illustrate the important role of RNases in mRNA turnover and gene regulation and show that repression of translation mediated by sRNA (also by translational repressor proteins) is often subsequently followed by mRNA degradation. All these regulatory events involve the catalytic activity of the enzymes. However, one cannot exclude that RNases might also regulate gene expression solely through their RNA binding activity. Notably, the dsRNA binding activity of RNase III has been reported to promote translation of lambda phage cIII RNA [150].

4.2. Modification of the Degradosome. The activity of RNases or other enzymes of the degradosome can be modulated. The first evidence of a modified degradosome came during a screen for suppressors of a cold-sensitive phenotype in a $c s d A$ mutant [151]. It was demonstrated that the RNA helicase, $c s d A$, becomes incorporated in the RNA degradosome complex in E. coli after cold shock [151] and it can functionally replace RhlB, the typical RNA helicase within the degradosome. It was proposed that the cold shockinduced CsdA associates with the degradosome to facilitate the unwinding of structured RNAs at cold temperatures. Furthermore, recent evidence revealed the association of the degradosome with components of central metabolism suggesting that these modified complexes may be part of a feedback network that allows the cell to coordinate RNA decay with metabolic conditions. In Caulobacter crescentus, the Krebs cycle enzyme aconitase was found associated with the degradosome as opposed to the glycolytic enzyme enolase that is found in E. coli [152]. Binding of aconitase to the complex occurred through interaction with RNase E and levels of RNase E varied during the cell cycle. The connection between RNA decay and central metabolism was further illustrated by the fact that citrate, a metabolite of the Krebs cycle, has an inhibitory effect on the activity of PNPase in $E$. coli [153]. It was recently pinpointed that an oxygen sensing system is able to adjust the level of c-di-GMP available to PNPase within a large ribonucleoprotein complex in E. coli and that this enhances PNPase activity [154]. Within this complex, PNPase, enolase, RNase E, RNA terminator protein Rho, several chaperone proteins (DnaJ, DnaK, GroEL), and oxygen-sensing proteins (DosC and DosP) were identified in addition to an RNA moiety [154]. Altogether these different studies have identified variations to the degradosome complex that confer to the cell the capacity to sense and adapt to environmental changes. It is expected that future work characterizing modifications of the degradosome complex and their impact on RNA decay will uncover connections between RNA regulation and global metabolism. 
Moreover, several examples have been highlighted where the activity of RNases can be cross-regulated. For instance, $E$. coli PNPase synthesis is autoregulated at the posttranscriptional level by an RNase III-dependent mechanism [155]. In fact, many of the RNases also appear to be regulated by a feedback mechanism and due to the fact that they are involved in rRNA processing, their expression is thus coordinated with ribosome synthesis [156-158]. Moreover, a protein regulator has been reported for E. coli RNase III [159]. One can envision sRNAs possibly having a role in modulating ribonuclease activity. As underscored above, the genomic context of the RNases might offer valuable cues towards understanding regulation of their expression. Stage of growth and different stresses emerge as common themes in regulation of RNases activity $[4,78]$. Surely our appreciation of regulation of RNase activity is far from being complete.

\section{Conclusions and Perspectives}

This paper highlights the importance of RNases in gene expression in several Gram-positive pathogenic bacteria. Furthermore, we have illustrated by several examples the roles of specific RNases in the regulation of the expression of mRNA targets involved in virulence. However, the full repertoire of targets for RNases, and the roles of accessory proteins (RNA helicases, RNA-binding proteins) in gene regulation still need to be assessed, especially in Gram-positive bacteria. Without doubt our knowledge will greatly advance from current methodologies such as deep sequencing and tiling arrays where the full RNome of a bacterium can be evaluated in wild-type and mutant backgrounds. Moreover, high-throughput sequencing combined with crosslinking immunoprecipitation (HITS-CLIP) has proven valuable for identifying RNA-protein interactions $[160,161]$. This method could also lead to identification of the set of target RNAs of an RNase. These new possibilities are expected to offer valuable insights into the function of these enzymes.

The emergence of antibiotic resistances amongst pathogenic bacteria urgently necessitates the discovery of novel drugs. Several possibilities of targeting components of the RNA decay machinery in the design of novel drugs have been reported. Recently, an inhibitory compound of RnpA was identified that proved to be effective against several strains of MRSA, biofilm associated S. aureus and against other Grampositive pathogens [75]. Despite the fact that the identified molecule exhibited cytotoxicity against a human cell line and cannot be further exploited, it nevertheless sets the foundation for novel antimicrobial strategies targeting the RNA degrading machinery. Riboswitches have also been investigated as possible drug targets. Efforts have been focused on designing ligands nonmetabolizable by the cell that can specifically target riboswitches and repress growth $[162$, 163]. TA systems have been suggested as good candidates for novel antibacterial strategies. Two modes of action have been envisioned for newly designed drugs aiming at activation of the toxin. The first approach involves turning down production of the antitoxin either at the transcriptional or the translational level whereas the second one aims at the disruption of the toxin-antitoxin interaction. In both cases, the result is degradation of the labile antitoxin and release of the toxin which ultimately results in self-inflicted cell death [164]. The emergence of antibiotic resistances often relies on the presence of resistance genes residing on mobile genetic elements like plasmids [125] which can be transferred to different species [127]. Since TA modules are responsible for stabilization of these elements, a strategy for targeting TA systems seems to hold promise for the design of novel antibiotics.

\section{Note Added in the Proof}

A recent study by Lasa et al. [165] revealed an RNA quality control function of $S$. aureus RNase III. The enzyme eliminates antisense RNA production by specific processing of sense-antisense complexes.

\section{Acknowledgments}

This work was supported by the "Centre National de la Recherche Scientifique" (CNRS), the "Agence Nationale pour la Recherche" (ANR10-Pathogenomics-ARMSA; P. Romby, E. Lioliou), and the labex NetRNA (PR). E. Lioliou has received the support of a long-term fellowship from FEBS.

\section{References}

[1] G. Storz, J. Vogel, and K. Wassarman, "Regulation by small RNAs in bacteria: expanding frontiers," Molecular Cell, vol. 43, no. 6, pp. 880-891, 2011.

[2] P. Romby and M. Springer, "Bacterial translational control at atomic resolution," Trends in Genetics, vol. 19, no. 3, pp. 155$161,2003$.

[3] J. G. Belasco, "All things must pass: contrasts and commonalities in eukaryotic and bacterial mRNA decay," Nature Reviews Molecular Cell Biology, vol. 11, no. 7, pp. 467-478, 2010.

[4] K. L. Anderson and P. M. Dunman, "Messenger RNA turnover processes in Escherichia coli, Bacillus subtilis, and emerging studies in Staphylococcus aureus," International Journal of Microbiology, vol. 2009, Article ID 525491, 15 pages, 2009.

[5] C. Condon, "Maturation and degradation of RNA in bacteria," Current Opinion in Microbiology, vol. 10, no. 3, pp. 271278, 2007.

[6] A. J. Carpousis, B. F. Luisi, and K. J. McDowall, "Endonucleolytic initiation of mRNA decay in Escherichia coli," Progress in Molecular Biology and Translational Science, vol. 85, pp. 91-135, 2009.

[7] D. H. Bechhofer, "Messenger RNA decay and maturation in Bacillus subtilis," Progress in Molecular Biology and Translational Science, vol. 85, pp. 231-273, 2009.

[8] M. Beaume, D. Hernandez, L. Farinelli et al., "Cartography of methicillin-resistant S. aureus transcripts: detection, orientation and temporal expression during growth phase and stress conditions," PLoS ONE, vol. 5, no. 5, Article ID e10725, 2010.

[9] C. M. Sharma, S. Hoffmann, F. Darfeuille et al., "The primary transcriptome of the major human pathogen Helicobacter pylori," Nature, vol. 464, no. 7286, pp. 250-255, 2010. 
[10] A. Toledo-Arana, O. Dussurget, G. Nikitas et al., "The Listeria transcriptional landscape from saprophytism to virulence," Nature, vol. 459, no. 7249, pp. 950-956, 2009.

[11] S. Rasmussen, H. B. Nielsen, and H. Jarmer, "The transcriptionally active regions in the genome of Bacillus subtilis," Molecular Microbiology, vol. 73, no. 6, pp. 1043-1057, 2009.

[12] K. Shahbabian, A. Jamalli, L. Zig, and H. Putzer, "RNase Y, a novel endoribonuclease, initiates riboswitch turnover in Bacillus subtilis," EMBO Journal, vol. 28, no. 22, pp. 35233533, 2009.

[13] F. M. Commichau, F. M. Rothe, C. Herzberg et al., "Novel activities of glycolytic enzymes in Bacillus subtilis: interactions with essential proteins involved in mRNA processing," Molecular and Cellular Proteomics, vol. 8, no. 6, pp. 13501360, 2009.

[14] M. Lehnik-Habrink, J. Newman, F. M. Rothe et al., "RNase $\mathrm{Y}$ in Bacillus subtilis: a natively disordered protein that is the functional equivalent of RNase E from Escherichia coli," Journal of Bacteriology, vol. 193, no. 19, pp. 5431-5441, 2011.

[15] M. Lehnik-Habrink, M. Schaffer, U. Mäder, C. Diethmaier, C. Herzberg, and J. Stülke, "RNA processing in Bacillus subtilis: identification of targets of the essential RNase Y," Molecular Microbiology, vol. 81, no. 6, pp. 1459-1473, 2011.

[16] C. Diethmaier, N. Pietack, K. Gunka et al., "A novel factor controlling bistability in Bacillus subtilis: the ymdb protein affects flagellin expression and biofilm formation," Journal of Bacteriology, vol. 193, no. 21, pp. 5997-6007, 2011.

[17] A. Hunt, J. P. Rawlins, H. B. Thomaides, and J. Errington, "Functional analysis of 11 putative essential genes in Bacillus subtilis," Microbiology, vol. 152, part 10, pp. 2895-2907, 2006.

[18] V. Khemici, L. Poljak, B. F. Luisi, and A. J. Carpousis, "The RNase E of Escherichia coli is a membrane-binding protein," Molecular Microbiology, vol. 70, no. 4, pp. 799-813, 2008.

[19] S. Even, O. Pellegrini, L. Zig et al., "Ribonucleases J1 and J2: two novel endoribonucleases in B.subtilis with functional homology to E.coli RNase E," Nucleic Acids Research, vol. 33, no. 7, pp. 2141-2152, 2005.

[20] K. Kobayashi, S. D. Ehrlich, A. Albertini et al., "Essential Bacillus subtilis genes," Proceedings of the National Academy of Sciences of the United States of America, vol. 100, no. 8, pp. 4678-4683, 2003.

[21] J. A. Newman, L. Hewitt, C. Rodrigues, A. Solovyova, C. R. Harwood, and R. J. Lewis, "Unusual, dual endo-and exonuclease activity in the degradosome explained by crystal structure analysis of RNase J1," Structure, vol. 19, no. 9, pp. 1241-1251, 2011.

[22] N. Mathy, L. Bénard, O. Pellegrini, R. Daou, T. Wen, and C. Condon, " 5 '-to- 3 ' exoribonuclease activity in bacteria: role of RNase J1 in rRNA maturation and 5' stability of mRNA," Cell, vol. 129, no. 4, pp. 681-692, 2007.

[23] N. Mathy, A. Hébert, P. Mervelet et al., "Bacillus subtilis ribonucleases J1 and J2 form a complex with altered enzyme behaviour," Molecular Microbiology, vol. 75, no. 2, pp. 489498, 2010.

[24] U. Mäder, L. Zig, J. Kretschmer, G. Homuth, and H. Putzer, "mRNA processing by RNases J1 and J2 affects Bacillus subtilis gene expression on a global scale," Molecular Microbiology, vol. 70, no. 1, pp. 183-196, 2008.

[25] Y. Redko and C. Condon, "Maturation of 23S rRNA in Bacillus subtilis in the absence of mini-III," Journal of Bacteriology, vol. 192, no. 1, pp. 356-359, 2010.

[26] I. L. de la Sierra-Gallay, L. Zig, A. Jamalli, and H. Putzer, "Structural insights into the dual activity of RNase J," Nature
Structural and Molecular Biology, vol. 15, no. 2, pp. 206-212, 2008.

[27] M. Lehnik-Habrink, H. Pförtner, L. Rempeters, N. Pietack, C. Herzberg, and J. Stülke, "The RNA degradosome in bacillus subtilis: identification of csha as the major RNA helicase in the multiprotein complex," Molecular Microbiology, vol. 77, no. 4, pp. 958-971, 2010.

[28] A. Dorléans, I. li de la Sierra-Gallay, J. Piton et al., "Molecular basis for the recognition and cleavage of RNA by the bifunctional 5'-3' exo/endoribonuclease RNase J," Structure, vol. 19, no. 9, pp. 1252-1261, 2011.

[29] M. F. Symmons, G. H. Jones, and B. F. Luisi, "A duplicated fold is the structural basis for polynucleotide phosphorylase catalytic activity, processivity, and regulation," Structure, vol. 8, no. 11, pp. 1215-1226, 2000.

[30] W. Wang and D. H. Bechhofer, "Properties of a Bacillus subtilis polynucleotide phosphorylase deletion strain," Journal of Bacteriology, vol. 178, no. 8, pp. 2375-2382, 1996.

[31] M. P. Deutscher and N. B. Reuven, "Enzymatic basis for hydrolytic versus phosphorolytic mRNA degradation in Escherichia coli and Bacillus subtilis," Proceedings of the National Academy of Sciences of the United States of America, vol. 88, no. 8, pp. 3277-3280, 1991.

[32] S. Mitra, K. Hue, and D. H. Bechhofer, "In vitro processing activity of Bacillus subtilis polynucleotide phosphorylase," Molecular Microbiology, vol. 19, no. 2, pp. 329-342, 1996.

[33] G. Deikus and D. H. Bechhofer, "Bacillus subtilis trp leader RNA. Rnase J1 endonuclease cleavage specificity and PNPase processing," Journal of Biological Chemistry, vol. 284, no. 39, pp. 26394-26401, 2009.

[34] P. P. Cardenas, B. Carrasco, H. Sanchez, G. Deikus, D. H. Bechhofer, and J. C. Alonso, "Bacillus subtilis polynucleotide phosphorylase $3^{\prime}$-to-5' DNase activity is involved in DNA repair," Nucleic Acids Research, vol. 37, no. 12, pp. 4157-4169, 2009.

[35] P. P. Cardenas, T. Carzaniga, S. Zangrossi et al., "Polynucleotide phosphorylase exonuclease and polymerase activities on single-stranded DNA ends are modulated by RecN, SsbA and RecA proteins," Nucleic Acids Research, vol. 39, no. 21, pp. 9250-9261, 2011.

[36] I. J. MacRae and J. A. Doudna, "Ribonuclease revisited: structural insights into ribonuclease III family enzymes," Current Opinion in Structural Biology, vol. 17, no. 1, pp. 138-145, 2007.

[37] V. N. Kim, J. Han, and M. C. Siomi, "Biogenesis of small RNAs in animals," Nature Reviews Molecular Cell Biology, vol. 10, no. 2, pp. 126-139, 2009.

[38] J. Blaszczyk, J. E. Tropea, M. Bubunenko et al., "Crystallographic and modeling studies of RNase III suggest a mechanism for double-stranded RNA cleavage," Structure, vol. 9, no. 12, pp. 1225-1236, 2001.

[39] H. Zhang, F. A. Kolb, L. Jaskiewicz, E. Westhof, and W. Filipowicz, "Single processing center models for human Dicer and bacterial RNase III," Cell, vol. 118, no. 1, pp. 57-68, 2004.

[40] Y. Redko, D. H. Bechhofer, and C. Condon, "Mini-III, an unusual member of the RNase III family of enzymes, catalyses 23 S ribosomal RNA maturation in B. subtilis," Molecular Microbiology, vol. 68, no. 5, pp. 1096-1106, 2008.

[41] I. Calin-Jageman and A. W. Nicholson, "Mutational analysis of an RNA internal loop as a reactivity epitope for Escherichia coli ribonuclease III substrates," Biochemistry, vol. 42, no. 17, pp. 5025-5034, 2003.

[42] H. Li and A. W. Nicholson, "Defining the enzyme binding domain of a ribonuclease III processing signal. Ethylation 
interference and hydroxyl radical footprinting using catalytically inactive RNase III mutants," EMBO Journal, vol. 15, no. 6, pp. 1421-1433, 1996.

[43] T. Franch, T. Thisted, and K. Gerdes, "Ribonuclease III processing of coaxially stacked RNA helices," Journal of Biological Chemistry, vol. 274, no. 37, pp. 26572-26578, 1999.

[44] C. Chevalier, S. Boisset, C. Romilly et al., "Staphylococcus aureus RNAIII binds to two distant regions of coa mRNA to arrest translation and promote mRNA degradation," PLoS Pathogens, vol. 6, no. 3, Article ID e1000809, 2010.

[45] W. Wang and D. H. Bechhofer, "Bacillus subtilis RNase III gene: cloning, function of the gene in Escherichia coli, and construction of Bacillus subtilis strains with altered rnc loci," Journal of Bacteriology, vol. 179, no. 23, pp. 7379-7385, 1997.

[46] M. B. Stead, S. Marshburn, B. K. Mohanty et al., "Analysis of Escherichia coli RNase e and RNase III activity in vivo using tiling microarrays," Nucleic Acids Research, vol. 39, no. 8, pp. 3188-3203, 2011.

[47] S. Yao, J. B. Blaustein, and D. H. Bechhofer, "Processing of Bacillus subtilis small cytoplasmic RNA: evidence for an additional endonuclease cleavage site," Nucleic Acids Research, vol. 35, no. 13, pp. 4464-4473, 2007.

[48] M. A. Herskovitz and D. H. Bechhofer, "Endoribonuclease RNase III is essential in Bacillus subtilis," Molecular Microbiology, vol. 38, no. 5, pp. 1027-1033, 2000.

[49] A. Oguro, H. Kakeshita, K. Nakamura, K. Yamane, W. Wang, and D. H. Bechhofer, "Bacillus subtilis RNase III cleaves both $5^{\prime}$-and $3^{\prime}$-sites of the small cytoplasmic RNA precursor," Journal of Biological Chemistry, vol. 273, no. 31, pp. 1954219547, 1998.

[50] A. V. Pertzev and A. W. Nicholson, "Characterization of RNA sequence determinants and antideterminants of processing reactivity for a minimal substrate of Escherichia coli ribonuclease III," Nucleic Acids Research, vol. 34, no. 13, pp. 37083721, 2006.

[51] A. V. Kazantsev and N. R. Pace, "Bacterial RNase P: a new view of an ancient enzyme," Nature Reviews Microbiology, vol. 4, no. 10, pp. 729-740, 2006.

[52] J. Hsieh, A. J. Andrews, and C. A. Fierke, "Roles of protein subunits in RNA-protein complexes: lessons from Ribonuclease P," Biopolymers, vol. 73, no. 1, pp. 79-89, 2004.

[53] E. Seif and S. Altman, "RNase P cleaves the adenine riboswitch and stabilizes pbuE mRNA in Bacillus subtilis," RNA, vol. 14, no. 6, pp. 1237-1243, 2008.

[54] S. Altman, "A view of RNase P," Molecular BioSystems, vol. 3, no. 9, pp. 604-607, 2007.

[55] A. Torres-Larios, K. K. Swinger, A. S. Krasilnikov, T. Pan, and A. Mondragón, "Crystal structure of the RNA component of bacterial ribonuclease P," Nature, vol. 437, no. 7058, pp. 584587, 2005.

[56] N. J. Reiter, A. Osterman, A. Torres-Larios, K. K. Swinger, T. Pan, and A. Mondragón, "Structure of a bacterial ribonuclease P holoenzyme in complex with tRNA," Nature, vol. 468, no. 7325, pp. 784-789, 2010.

[57] O. Esakova and A. S. Krasilnikov, "Of proteins and RNA: the RNase P/MRP family," RNA, vol. 16, no. 9, pp. 1725-1747, 2010.

[58] H. Celesnik, A. Deana, and J. G. Belasco, "Initiation of RNA decay in Escherichia coli by $5^{\prime}$ pyrophosphate removal," Molecular Cell, vol. 27, no. 1, pp. 79-90, 2007.

[59] J. Richards, Q. Liu, O. Pellegrini et al., "An RNA pyrophosphohydrolase triggers $5^{\prime}$-exonucleolytic degradation of mRNA in Bacillus subtilis," Molecular Cell, vol. 43, no. 6, pp. 940-949, 2011.
[60] S. H. Ling, R. Qamra, and H. Song, "Structural and functional insights into eukaryotic mRNA decapping," Wiley Interdisciplinary Reviews, vol. 2, no. 2, pp. 193-208, 2011.

[61] B. Py, H. Causton, E. A. Mudd, and C. F. Higgins, "A protein complex mediating mRNA degradation in Escherichia coli," Molecular Microbiology, vol. 14, no. 4, pp. 717-729, 1994.

[62] A. J. Carpousis, G. van Houwe, C. Ehretsmann, and H. M. Krisch, "Copurification of E. coli RNAase E and PNPase: evidence for a specific association between two enzymes important in RNA processing and degradation," Cell, vol. 76, no. 5, pp. 889-900, 1994.

[63] B. Py, C. F. Higgins, H. M. Krisch, and A. J. Carpousis, "A DEAD-box RNA helicase in the Escherichia coli RNA degradosome," Nature, vol. 381, no. 6578, pp. 169-172, 1996.

[64] C. M. Roux, J. P. DeMuth, and P. M. Dunman, "Characterization of components of the Staphylococcus aureus mRNA degradosome holoenzyme-like complex," Journal of Bacteriology, vol. 193, no. 19, pp. 5520-5526, 2011.

[65] E. P. C. Rocha, "The organization of the bacterial genome," Annual Review of Genetics, vol. 42, pp. 211-233, 2008.

[66] S. Yao and D. H. Bechhofer, "Initiation of decay of Bacillus subtilis rpsO mRNA by endoribonuclease RNase Y," Journal of Bacteriology, vol. 192, no. 13, pp. 3279-3286, 2010.

[67] M. L. Gatewood, P. Bralley, and G. H. Jones, "Rnase IIIdependent expression of the rpsO-pnp operon of Streptomyces coelicolor," Journal of Bacteriology, vol. 193, no. 17, pp. 4371-4379, 2011.

[68] P. Gao, K. L. Pinkston, S. R. Nallapareddy, A. van Hoof, B. E. Murray, and B. R. Harvey, "Enterococcus faecalis rnjB is required for pilin gene expression and biofilm formation," Journal of Bacteriology, vol. 192, no. 20, pp. 5489-5498, 2010.

[69] H. Kakeshita, A. Oguro, R. Amikura, K. Nakamura, and K. Yamane, "Expression of the $\mathrm{ftsY}$ gene encoding a homologue of the $\alpha$ subunit of mammalian signal recognition particle receptor, is controlled by different promoters in vegetative and sporulating cells of Bacillus subtilis," Microbiology, vol. 146, part 10, pp. 2595-2603, 2000.

[70] E. Ramirez-Peña, J. Treviño, Z. Liu, N. Perez, and P. Sumby, "The group A Streptococcus small regulatory RNA FasX enhances streptokinase activity by increasing the stability of the ska mRNA transcript," Molecular Microbiology, vol. 78, no. 6, pp. 1332-1347, 2010.

[71] S. Boisset, T. Geissmann, E. Huntzinger et al., "Staphylococcus aureus RNAIII coordinately represses the synthesis of virulence factors and the transcription regulator Rot by an antisense mechanism," Genes and Development, vol. 21, no. 11, pp. 1353-1366, 2007.

[72] E. Huntzinger, S. Boisset, C. Saveanu et al., "Staphylococcus aureus RNAIII and the endoribonuclease III coordinately regulate spa gene expression," EMBO Journal, vol. 24, no. 4, pp. 824-835, 2005.

[73] J. M. Silvaggi, J. B. Perkins, and R. Losick, "Small untranslated RNA antitoxin in Bacillus subtilis," Journal of Bacteriology, vol. 187, no. 19, pp. 6641-6650, 2005.

[74] N. J. P. ten Broeke-Smits, T. E. Pronk, I. Jongerius et al., "Operon structure of Staphylococcus aureus," Nucleic Acids Research, vol. 38, no. 10, Article ID gkq058, pp. 3263-3274, 2010.

[75] P. D. Olson, L. J. Kuechenmeister, K. L. Anderson et al., "Small molecule inhibitors of staphylococcus aureus RnpA alter cellular mRNA turnover, exhibit antimicrobial activity, and attenuate pathogenesis," PLoS Pathogens, vol. 7, no. 2, Article ID e1001287, 2011. 
[76] E. A. Bancroft, "Antimicrobial resistance: it's not just for hospitals," Journal of the American Medical Association, vol. 298, no. 15, pp. 1803-1804, 2007.

[77] R. M. Klevens, M. A. Morrison, J. Nadle et al., "Invasive methicillin-resistant Staphylococcus aureus infections in the United States," Journal of the American Medical Association, vol. 298, no. 15, pp. 1763-1771, 2007.

[78] J. V. Bugrysheva and J. R. Scott, "Regulation of virulence gene expression in Streptococcus pyogenes: determinants of differential mRNA decay," RNA Biology, vol. 7, no. 5, pp. 569$572,2010$.

[79] T. C. Barnett, J. V. Bugrysheva, and J. R. Scott, "Role of mRNA stability in growth phase regulation of gene expression in the group A Streptococcus," Journal of Bacteriology, vol. 189, no. 5, pp. 1866-1873, 2007.

[80] J. V. Bugrysheva and J. R. Scott, "The ribonucleases J1 and J2 are essential for growth and have independent roles in mRNA decay in Streptococcus pyogenes," Molecular Microbiology, vol. 75, no. 3, pp. 731-743, 2010.

[81] C. Kaito, K. Kurokawa, Y. Matsumoto et al., "Silkworm pathogenic bacteria infection model for identification of novel virulence genes," Molecular Microbiology, vol. 56, no. 4, pp. 934-944, 2005.

[82] S. O. Kang, M. G. Caparon, and K. H. Cho, "Virulence gene regulation by CvfA, a putative RNase: the CvfA-enolase complex in Streptococcus pyogenes links nutritional stress, growth-phase control, and virulence gene expression," Infection and Immunity, vol. 78, no. 6, pp. 2754-2767, 2010.

[83] M. Nagata, C. Kaito, and K. Sekimizu, "Phosphodiesterase activity of CvfA is required for virulence in Staphylococcus aureus," Journal of Biological Chemistry, vol. 283, no. 4, pp. 2176-2184, 2008.

[84] K. Steiner and H. Malke, "Life in protein-rich environments: the relA-independent response of Streptococcus pyogenes to amino acid starvation," Molecular Microbiology, vol. 38, no. 5, pp. 1004-1016, 2000.

[85] K. L. Anderson, C. Roberts, T. Disz et al., "Characterization of the Staphylococcus aureus heat shock, cold shock, stringent, and SOS responses and their effects on log-phase mRNA turnover," Journal of Bacteriology, vol. 188, no. 19, pp. 67396756, 2006.

[86] K. L. Anderson, C. M. Roux, M. W. Olson et al., "Characterizing the effects of inorganic acid and alkaline shock on the Staphylococcus aureus transcriptome and messenger RNA turnover," FEMS Immunology and Medical Microbiology, vol. 60, no. 3, pp. 208-250, 2010.

[87] A. Lawal, O. Jejelowo, A. K. Chopra, and J. A. Rosenzweig, "Ribonucleases and bacterial virulence," Microbial Biotechnology, vol. 4, no. 5, pp. 558-571, 2011.

[88] T. Geissmann, C. Chevalier, M. Cros et al., "A search for small noncoding RNAs in Staphylococcus aureus reveals a conserved sequence motif for regulation," Nucleic Acids Research, vol. 37, no. 21, Article ID gkp668, pp. 7239-7257, 2009.

[89] K. Ohtani, H. Hirakawa, K. Tashiro, S. Yoshizawa, S. Kuhara, and T. Shimizu, "Identification of a two-component VirR/ VirS regulon in Clostridium perfringens," Anaerobe, vol. 16, no. 3, pp. 258-264, 2010.

[90] N. Obana, Y. Shirahama, K. Abe, and K. Nakamura, "Stabilization of Clostridium perfringens collagenase mRNA by VR-RNA-dependent cleavage in $5^{\prime}$ leader sequence," Molecular Microbiology, vol. 77, no. 6, pp. 1416-1428, 2010.

[91] A. I. Hidron, J. R. Edwards, J. Patel et al., "NHSN annual update: antimicrobial-resistant pathogens associated with healthcare-associated infections: annual summary of data reported to the National Healthcare Safety Network at the Centers for Disease Control and Prevention, 2006-2007," Infection Control and Hospital Epidemiology, vol. 29, no. 11, pp. 996-1011, 2008.

[92] T. Proft and E. N. Baker, "Pili in Gram-negative and Grampositive bacteria-structure, assembly and their role in disease," Cellular and Molecular Life Sciences, vol. 66, no. 4, pp. 613-635, 2009.

[93] R. P. Novick and E. Geisinger, "Quorum sensing in staphylococci," Annual Review of Genetics, vol. 42, pp. 541-564, 2008.

[94] C. Bohn, C. Rigoulay, S. Chabelskaya et al., "Experimental discovery of small RNAs in Staphylococcus aureus reveals a riboregulator of central metabolism," Nucleic Acids Research, vol. 38, no. 19, Article ID gkq462, pp. 6620-6636, 2010.

[95] B. Felden, F. Vandenesch, P. Bouloc, and P. Romby, "The Staphylococcus aureus RNome and its commitment to virulence," PLoS Pathogens, vol. 7, no. 3, Article ID e1002006, 2011.

[96] C. Pichon and B. Felden, "Small RNA genes expressed from Staphylococcus aureus genomic and pathogenicity islands with specific expression among pathogenic strains," Proceedings of the National Academy of Sciences of the United States of America, vol. 102, no. 40, pp. 14249-14254, 2005.

[97] Y. Liu, J. Dong, N. Wu et al., "The production of extracellular proteins is regulated by ribonuclease III via two different pathways in Staphylococcus aureus," PLoS ONE, vol. 6, no. 5, Article ID e20554, 2011.

[98] H. Aiba, "Mechanism of RNA silencing by Hfq-binding small RNAs," Current Opinion in Microbiology, vol. 10, no. 2, pp. 134-139, 2007.

[99] P. Romby and E. Charpentier, "An overview of RNAs with regulatory functions in gram-positive bacteria," Cellular and Molecular Life Sciences, vol. 67, no. 2, pp. 217-237, 2010.

[100] J. S. Nielsen, L. K. Lei, T. Ebersbach et al., "Defining a role for Hfq in Gram-positive bacteria: evidence for Hfq-dependent antisense regulation in Listeria monocytogenes," Nucleic Acids Research, vol. 38, no. 3, Article ID gkp1081, pp. 907-919, 2009.

[101] J. S. Nielsen, M. H. Larsen, E. M. S. Lillebæk et al., "A small RNA controls expression of the chitinase ChiA in listeria monocytogenes," PLoS ONE, vol. 6, no. 4, Article ID e19019, 2011.

[102] E. Deltcheva, K. Chylinski, C. M. Sharma et al., "CRISPR RNA maturation by trans-encoded small RNA and host factor RNase III," Nature, vol. 471, no. 7340, pp. 602-607, 2011.

[103] L. A. Marraffini and E. J. Sontheimer, "CRISPR interference limits horizontal gene transfer in staphylococci by targeting DNA," Science, vol. 322, no. 5909, pp. 1843-1845, 2008.

[104] L. A. Marraffini and E. J. Sontheimer, "Self versus non-self discrimination during CRISPR RNA-directed immunity," Nature, vol. 463, no. 7280, pp. 568-571, 2010.

[105] R. Barrangou, C. Fremaux, H. Deveau et al., "CRISPR provides acquired resistance against viruses in prokaryotes," Science, vol. 315, no. 5819, pp. 1709-1712, 2007.

[106] P. Horvath and R. Barrangou, "CRISPR/Cas, the immune system of Bacteria and archaea," Science, vol. 327, no. 5962, pp. 167-170, 2010.

[107] T. Sinkunas, G. Gasiunas, C. Fremaux, R. Barrangou, P. Horvath, and V. Siksnys, "Cas3 is a single-stranded DNA nuclease and ATP-dependent helicase in the CRISPR/Cas immune system," EMBO Journal, vol. 30, no. 7, pp. 13351342, 2011. 
[108] R. R. Breaker, "Riboswitches: from ancient gene-control systems to modern drug targets," Future Microbiology, vol. 4, no. 7, pp. 771-773, 2009.

[109] E. R. Lee, J. L. Baker, Z. Weinberg, N. Sudarsan, and R. R. Breaker, "An allosteric self-splicing ribozyme triggered by a bacterial second messenger," Science, vol. 329, no. 5993, pp. 845-848, 2010.

[110] A. G. Y. Chen, N. Sudarsan, and R. R. Breaker, "Mechanism for gene control by a natural allosteric group I ribozyme," RNA, vol. 17, no. 11, pp. 1967-1972, 2011.

[111] J. A. Collins, I. Irnov, S. Baker, and W. C. Winkler, "Mechanism of mRNA destabilization by the glmS ribozyme," Genes and Development, vol. 21, no. 24, pp. 3356-3368, 2007.

[112] H. Engelberg-Kulka, S. Amitai, I. Kolodkin-Gal, and R. Hazan, "Bacterial programmed cell death and multicellular behavior in bacteria," PLoS Genetics, vol. 2, no. 10, article e135, 2006.

[113] Y. Yamaguchi and M. Inouye, "mRNA interferases, sequencespecific endoribonucleases from the toxin-antitoxin systems," Progress in Molecular Biology and Translational Science, vol. 85, pp. 467-500, 2009.

[114] K. Gerdes, S. K. Christensen, and A. Løbner-Olesen, "Prokaryotic toxin-antitoxin stress response loci," Nature Reviews Microbiology, vol. 3, no. 5, pp. 371-382, 2005.

[115] T. R. Blower, G. P. C. Salmond, and B. F. Luisi, "Balancing at survival's edge: the structure and adaptive benefits of prokaryotic toxin-antitoxin partners," Current Opinion in Structural Biology, vol. 21, no. 1, pp. 109-118, 2011.

[116] E. M. Fozo, M. R. Hemm, and G. Storz, "Small toxic proteins and the antisense RNAs that repress them," Microbiology and Molecular Biology Reviews, vol. 72, no. 4, pp. 579-589, 2008, Table of Contents.

[117] D. P. Pandey and K. Gerdes, "Toxin-antitoxin loci are highly abundant in free-living but lost from host-associated prokaryotes," Nucleic Acids Research, vol. 33, no. 3, pp. 966-976, 2005.

[118] K. Gerdes and E. G. H. Wagner, "RNA antitoxins," Current Opinion in Microbiology, vol. 10, no. 2, pp. 117-124, 2007.

[119] T. R. Blower, X. Y. Pei, F. L. Short et al., "A processed noncoding RNA regulates an altruistic bacterial antiviral system," Nature Structural and Molecular Biology, vol. 18, no. 2, pp. 185-191, 2011.

[120] P. C. Fineran, T. R. Blower, I. J. Foulds, D. P. Humphreys, K. S. Lilley, and G. P. C. Salmond, "The phage abortive infection system, ToxIN, functions as a protein-RNA toxin-antitoxin pair," Proceedings of the National Academy of Sciences of the United States of America, vol. 106, no. 3, pp. 894-899, 2009.

[121] J. H. Park, Y. Yamaguchi, and M. Inouye, "Bacillus subtilis MazF-bs (EndoA) is a UACAU-specific mRNA interferase," FEBS Letters, vol. 585, no. 15, pp. 2526-2532, 2011.

[122] O. Pellegrini, N. Mathy, A. Gogos, L. Shapiro, and C. Condon, "The Bacillus subtilis ydcDE operon encodes an endoribonuclease of the MazF/PemK family and its inhibitor," Molecular Microbiology, vol. 56, no. 5, pp. 1139-1148, 2005.

[123] X. Wu, X. Wang, K. Drlica, and X. Zhao, "A toxin-antitoxin module in Bacillus subtilis can both mitigate and amplify effects of lethal stress," PLOS ONE, vol. 6, no. 8, Article ID e23909, 2011.

[124] S. Agarwal, N. K. Mishra, S. Bhatnagar, and R. Bhatnagar, "PemK toxin of Bacillus anthracis is a ribonuclease: an insight into its active site, structure, and function," Journal of Biological Chemistry, vol. 285, no. 10, pp. 7254-7270, 2010.
[125] E. M. Moritz and P. J. Hergenrother, "Toxin-antitoxin systems are ubiquitous and plasmid-encoded in vancomycinresistant enterococci," Proceedings of the National Academy of Sciences of the United States of America, vol. 104, no. 1, pp. 311-316, 2007.

[126] E. M. Halvorsen, J. J. Williams, A. J. Bhimani, E. A. Billings, and P. J. Hergenrother, "Txe, an endoribonuclease of the enterococcal Axe-Txe toxin-antitoxin system, cleaves mRNA and inhibits protein synthesis," Microbiology, vol. 157, part 2, pp. 387-397, 2011.

[127] L. M. Weigel, D. B. Clewell, S. R. Gill et al., "Genetic analysis of a high-level vancomycin-resistant isolate of Staphylococcus aureus," Science, vol. 302, no. 5650, pp. 1569-1571, 2003.

[128] Z. Fu, N. P. Donegan, G. Memmi, and A. L. Cheung, "Characterization of $\mathrm{mazF}_{\mathrm{Sa}}$, an endoribonuclease from Staphylococcus aureus," Journal of Bacteriology, vol. 189, no. 24, pp. 8871-8879, 2007.

[129] L. Zhu, K. Inoue, S. Yoshizumi et al., "Staphylococcus aureus MazF specifically cleaves a pentad sequence, UACAU, which is unusually abundant in the mRNA for pathogenic adhesive factor SraP," Journal of Bacteriology, vol. 191, no. 10, pp. 3248-3255, 2009.

[130] Z. Fu, S. Tamber, G. Memmi, N. P. Donegan, and A. L. Cheung, "Overexpression of mazF $_{\mathrm{Sa}}$ in Staphylococcus aureus induces bacteriostasis by selectively targeting mRNAs for cleavage," Journal of Bacteriology, vol. 191, no. 7, pp. 20512059, 2009.

[131] N. P. Donegan and A. L. Cheung, "Regulation of the mazEF toxin-antitoxin module in Staphylococcus aureus and its impact on sigB expression," Journal of Bacteriology, vol. 191, no. 8, pp. 2795-2805, 2009.

[132] M. Bischoff, P. Dunman, J. Kormanec et al., "Microarraybased analysis of the Staphylococcus aureus $\sigma^{\mathrm{B}}$ regulon," Journal of Bacteriology, vol. 186, no. 13, pp. 4085-4099, 2004.

[133] J. J. Williams, E. M. Halvorsen, E. M. Dwyer, R. M. Difazio, and P. J. Hergenrother, "Toxin-antitoxin (TA) systems are prevalent and transcribed in clinical isolates of Pseudomonas aeruginosa and methicillin-resistant Staphylococcus aureus," FEMS Microbiology Letters, vol. 322, no. 1, pp. 41-50, 2011.

[134] O. Vesper, S. Amitai, M. Belitsky et al., "Selective translation of leaderless mRNAs by specialized ribosomes generated by MazF in Escherichia coli," Cell, vol. 147, no. 1, pp. 147-157, 2011.

[135] H. R. Ramage, L. E. Connolly, and J. S. Cox, "Comprehensive functional analysis of Mycobacterium tuberculosis toxin-antitoxin systems: implications for pathogenesis, stress responses, and evolution," PLoS Genetics, vol. 5, no. 12, Article ID e1000767, 2009.

[136] B. A. Ahidjo, D. Kuhnert, J. L. McKenzie et al., "VapC toxins from Mycobacterium tuberculosis are ribonucleases that differentially inhibit growth and are neutralized by cognate vapB antitoxins," PLoS ONE, vol. 6, no. 6, Article ID e21738, 2011.

[137] K. S. Winther and K. Gerdes, "Enteric virulence associated protein VapC inhibits translation by cleavage of initiator tRNA," Proceedings of the National Academy of Sciences of the United States of America, vol. 108, no. 18, pp. 7403-7407, 2011.

[138] L. Aussel, W. Zhao, M. Hébrard et al., "Salmonella detoxifying enzymes are sufficient to cope with the host oxidative burst," Molecular Microbiology, vol. 80, no. 3, pp. 628-640, 2011.

[139] K. Lewis, "Persister cells," Annual Review of Microbiology, vol. 64, pp. 357-372, 2010. 
[140] E. Maisonneuve, L. J. Shakespeare, M. G. Jørgensen, and K. Gerdes, "Bacterial persistence by RNA endonucleases," Proceedings of the National Academy of Sciences of the United States of America, vol. 108, no. 32, pp. 13206-13211, 2011.

[141] I. Keren, S. Minami, E. Rubin, and K. Lewis, "Characterization and transcriptome analysis of mycobacterium tuberculosis persisters," mBio, vol. 2, no. 3, pp. e00100-e00111, 2011.

[142] M. C. Chopin, A. Chopin, and E. Bidnenko, "Phage abortive infection in lactococci: variations on a theme," Current Opinion in Microbiology, vol. 8, no. 4, pp. 473-479, 2005.

[143] J. M. Andrade and C. M. Arraiano, "PNPase is a key player in the regulation of small RNAs that control the expression of outer membrane proteins," RNA, vol. 14, no. 3, pp. 543-551, 2008.

[144] N. de Lay and S. Gottesman, "Role of polynucleotide phosphorylase in sRNA function in Escherichia coli," RNA, vol. 17, no. 6, pp. 1172-1189, 2011.

[145] S. C. Viegas, I. J. Silva, M. Saramago, S. Domingues, and C. M. Arraiano, "Regulation of the small regulatory RNA MicA by ribonuclease III: a target-dependent pathway," Nucleic Acids Research, vol. 39, no. 7, pp. 2918-2930, 2011.

[146] S. C. Viegas and C. M. Arraiano, "Regulating the regulators: how ribonucleases dictate the rules in the control of small non-coding RNAs," RNA Biology, vol. 5, no. 4, pp. 230-243, 2008.

[147] K. Prévost, G. Desnoyers, J. F. Jacques, F. Lavoie, and E. Massé, "Small RNA-induced mRNA degradation achieved through both translation block and activated cleavage," Genes and Development, vol. 25, no. 4, pp. 385-396, 2011.

[148] S. P. Pandey, B. K. Minesinger, J. Kumar, and G. C. Walker, "A highly conserved protein of unknown function in Sinorhizobium meliloti affects sRNA regulation similar to Hfq," Nucleic Acids Research, vol. 39, no. 11, pp. 4691-4708, 2011.

[149] A. Gaballa, H. Antelmann, C. Aguilar et al., "The Bacillus subtilis iron-sparing response is mediated by a Fur-regulated small RNA and three small, basic proteins," Proceedings of the National Academy of Sciences of the United States of America, vol. 105, no. 33, pp. 11927-11932, 2008.

[150] S. Altuvia, H. Locker-Giladi, S. Koby, O. Ben-Nun, and A. B. Oppenheim, "RNase III stimulates the translation of the cIII gene of bacteriophage lambda," Proceedings of the National Academy of Sciences of the United States of America, vol. 84, no. 18 , pp. 6511-6515, 1987.

[151] A. Prud'homme-Géńreux, R. K. Beran, I. Iost, C. S. Ramey, G. A. Mackie, and R. W. Simons, "Physical and functional interactions among RNase E, polynucleotide phosphorylase and the cold-shock protein, CsdA: evidence for a 'cold shock degradosome," Molecular Microbiology, vol. 54, no. 5, pp. 1409-1421, 2004.

[152] S. W. Hardwick, V. S.Y. Chan, R. W. Broadhurst, and B. F. Luisi, "An RNA degradosome assembly in Caulobacter crescentus," Nucleic Acids Research, vol. 39, no. 4, pp. 14491459, 2011.

[153] S. Nurmohamed, H. A. Vincent, C. M. Titman et al., "Polynucleotide phosphorylase activity may be modulated by metabolites in Escherichia coli," Journal of Biological Chemistry, vol. 286, no. 16, pp. 14315-14323, 2011.

[154] J. R. Tuckerman, G. Gonzalez, and M. A. Gilles-Gonzalez, "Cyclic di-GMP activation of polynucleotide phosphorylase signal-dependent RNA processing," Journal of Molecular Biology, vol. 407, no. 5, pp. 633-639, 2011.
[155] A. C. Jarrige, N. Mathy, and C. Portier, "PNPase autocontrols its expression by degrading a double-stranded structure in the pnp mRNA leader," EMBO Journal, vol. 20, no. 23, pp. 6845-6855, 2001.

[156] W. Xu, J. Huang, and S. N. Cohen, "Autoregulation of absB (RNase III) expression in Streptomyces coelicolor by endoribonucleolytic cleavage of absB operon transcripts," Journal of Bacteriology, vol. 190, no. 15, pp. 5526-5530, 2008.

[157] J. C. A. Bardwell, P. Regnier, S. M. Chen, Y. Nakamura, M. Grunberg-Manago, and D. L. Court, "Autoregulation of RNase III operon by mRNA processing," EMBO Journal, vol. 8, no. 11, pp. 3401-3407, 1989.

[158] C. Jain and J. G. Belasco, "RNase E autoregulates its synthesis by controlling the degradation rate of its own mRNA in Escherichia coli: unusual sensitivity of the rne transcript to RNase E activity," Genes and Development, vol. 9, no. 1, pp. 84-96, 1995.

[159] K. S. Kim, R. Manasherob, and S. N. Cohen, "YmdB: a stressresponsive ribonuclease-binding regulator of E. coli RNase III activity," Genes and Development, vol. 22, no. 24, pp. 34973508, 2008.

[160] D. D. Licatalosi, A. Mele, J. J. Fak et al., "HITS-CLIP yields genome-wide insights into brain alternative RNA processing," Nature, vol. 456, no. 7221, pp. 464-469, 2008.

[161] S. W. Chi, J. B. Zang, A. Mele, and R. B. Darnell, "Argonaute HITS-CLIP decodes microRNA-mRNA interaction maps," Nature, vol. 460, no. 7254, pp. 479-486, 2009.

[162] K. F. Blount and R. R. Breaker, "Riboswitches as antibacterial drug targets," Nature Biotechnology, vol. 24, no. 12, pp. 15581564, 2006.

[163] J. Mulhbacher, P. St-Pierre, and D. A. Lafontaine, "Therapeutic applications of ribozymes and riboswitches," Current Opinion in Pharmacology, vol. 10, no. 5, pp. 551-556, 2010.

[164] J. J. Williams and P. J. Hergenrother, "Exposing plasmids as the Achilles' heel of drug-resistant bacteria," Current Opinion in Chemical Biology, vol. 12, no. 4, pp. 389-399, 2008.

[165] I. Lasa, A. Toledo-Arana, A. Dobin et al., "Genome-wide antisense transcription drives mRNA processing in bacteria," Proceedings of the National Academy of Sciences of the United States of America, vol. 108, no. 50, pp. 20172-20177, 2011. 

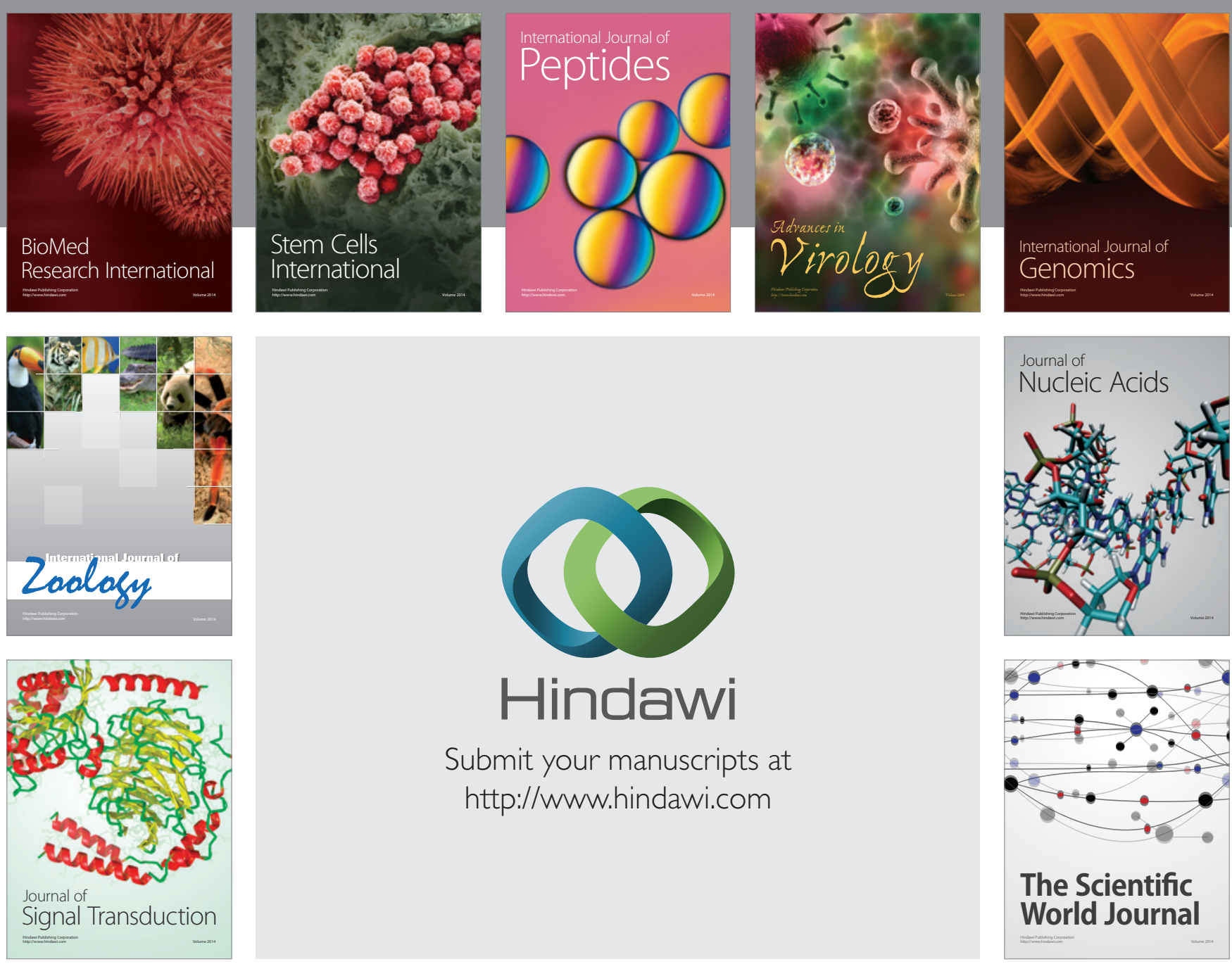

Submit your manuscripts at

http://www.hindawi.com
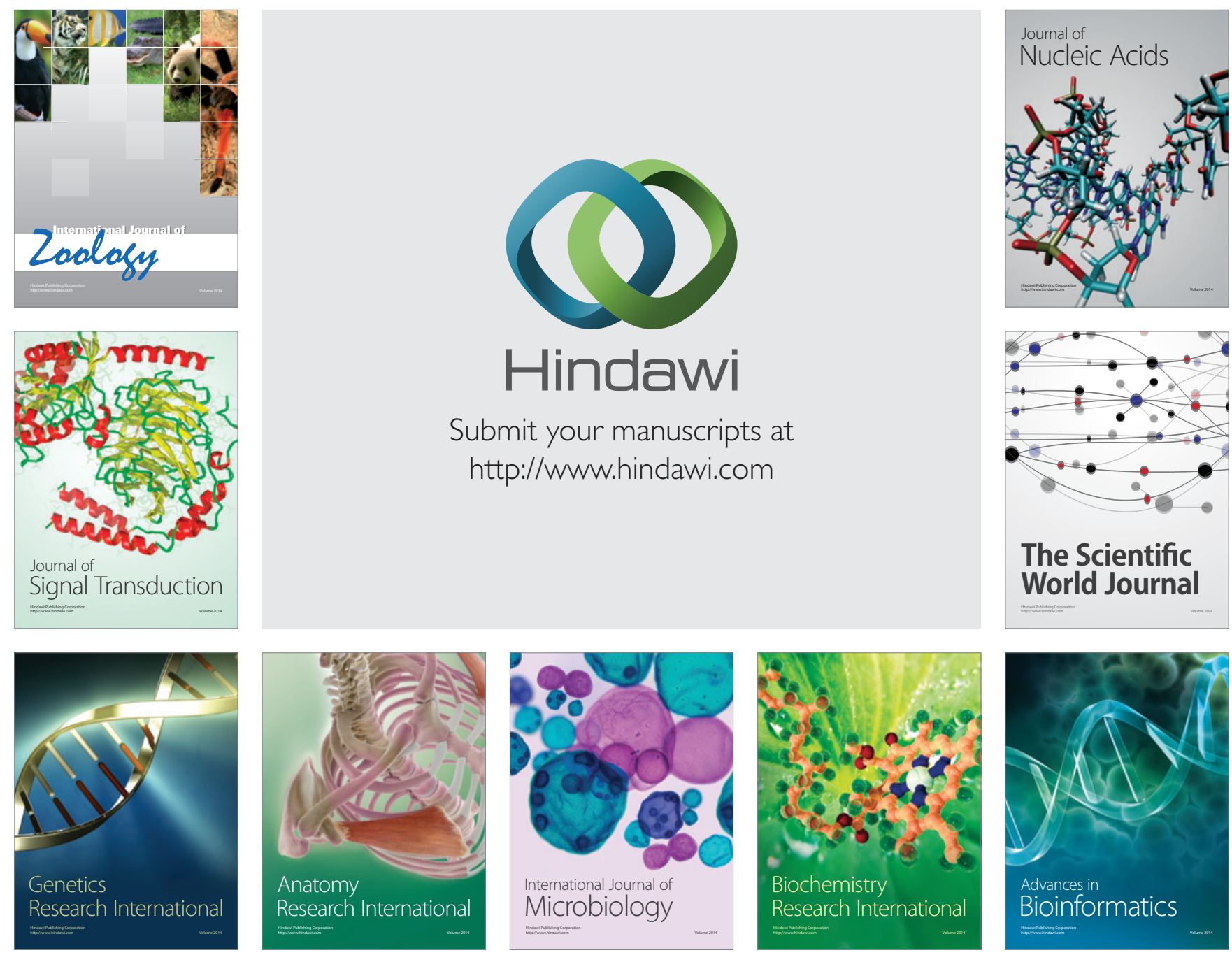

The Scientific World Journal
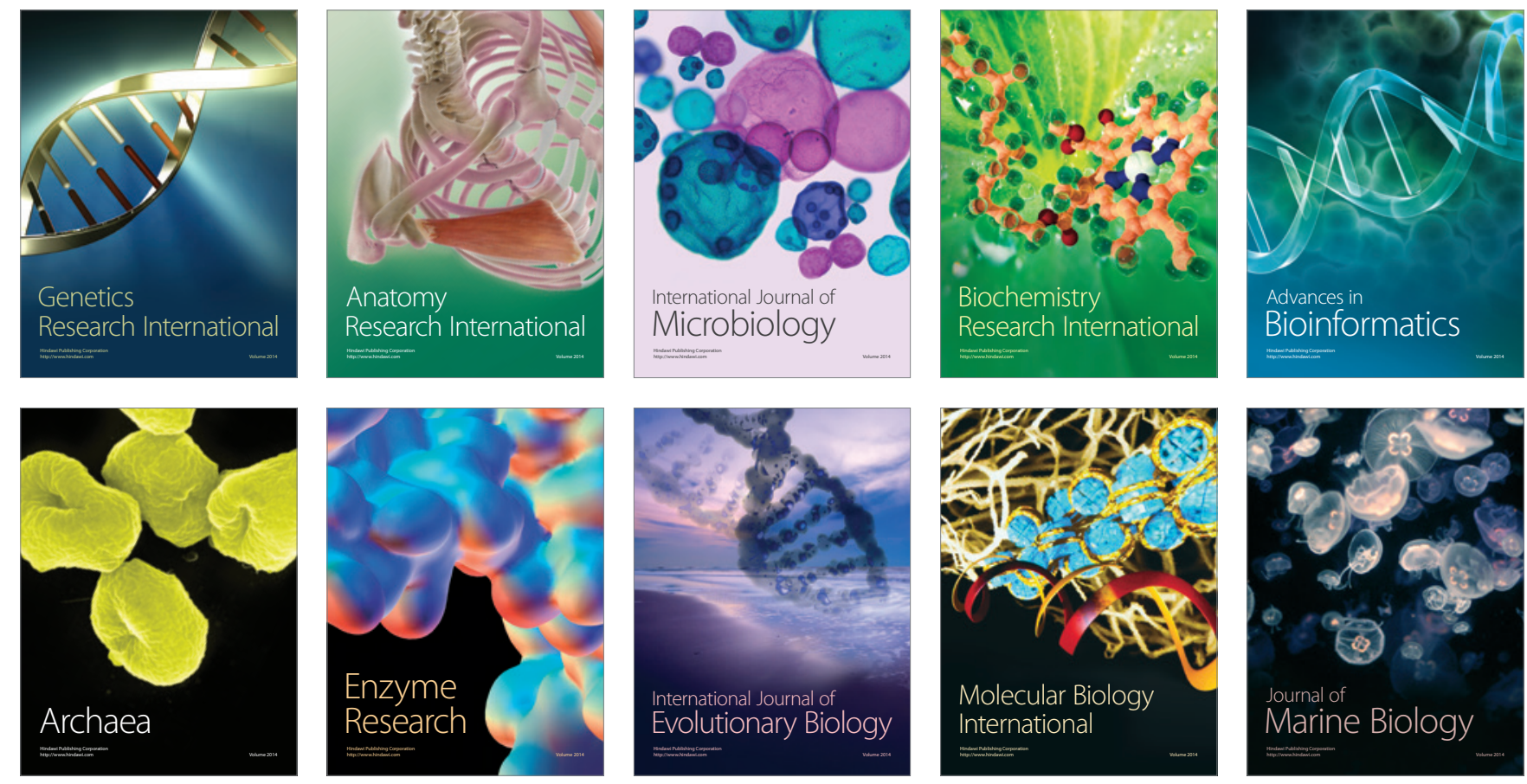